OPEN ACCESS

Edited by:

Thor Eysteinsson,

University of Iceland, Iceland

Reviewed by:

David J. Calkins,

Vanderbilt University Medical Center,

United States

Zhongfeng Wang,

Fudan University, China

${ }^{*}$ Correspondence: Scott Nawy

nawy@berkeley.edu

Received: 20 March 2020 Accepted: 25 June 2020 Published: 24 July 2020

Citation: Sladek AL and Nawy S (2020) Ocular Hypertension Drives Remodeling of AMPA Receptors in Select

Populations of Retinal Ganglion Cells. Front. Synaptic Neurosci. 12:30. doi: 10.3389/fnsyn.2020.00030

\section{Ocular Hypertension Drives Remodeling of AMPA Receptors in Select Populations of Retinal Ganglion Cells}

\author{
Asia L. Sladek and Scott Nawy* \\ Department of Ophthalmology and Visual Sciences, Truhlsen Eye Institute, University of Nebraska Medical Center, Omaha, \\ NE, United States
}

AMPA-type glutamate receptors in the CNS are normally impermeable to $\mathrm{Ca}^{2+}$, but the aberrant expression of $\mathrm{Ca}^{2+}$-permeable AMPA receptors (CP-AMPARs) occurs in pathological conditions such as ischemia or epilepsy, or degenerative diseases such as ALS. Here, we show that select populations of retinal ganglion cells (RGCs) similarly express high levels of CP-AMPARs in a mouse model of glaucoma. CP-AMPAR expression increased dramatically in both On sustained alpha and Off transient alpha RGCs, and this increase was prevented by genomic editing of the GluA2 subunit. On sustained alpha RGCs with elevated CP-AMPAR levels displayed profound synaptic depression, which was reduced by selectively blocking CP-AMPARs, buffering $\mathrm{Ca}^{2+}$ with BAPTA, or with the CB1 antagonist AM251, suggesting that depression was mediated by a retrograde transmitter which might be triggered by the influx of $\mathrm{Ca}^{2+}$ through $\mathrm{CP}$ AMPARs. Thus, glaucoma may alter the composition of AMPARs and depress excitatory synaptic input in select populations of RGCs.

\begin{abstract}
Keywords: glaucoma, AMPA receptors, ganglion cells, paired-pulse depression, optogenetic stimulation, currentvoltage relation, ocular hypertension
\end{abstract}

\section{INTRODUCTION}

Glaucoma is a neurodegenerative disease of retinal ganglion cells (RGCs) often associated with elevated intraocular pressure (IOP). Several mouse models have been developed to induce IOP, including injection of microspheres which reduce aqueous outflow through the trabecular meshwork, causing a long-lasting increase in ocular pressure (Sappington et al., 2010). Within 1 week following the elevation of IOP, there are several morphological and functional changes in RGCs including deficits in axonal transport (Buckingham et al., 2008; Crish et al., 2010; Calkins, 2012; Ward et al., 2014), loss of dendrites and sites of synaptic contacts (Della Santina et al., 2013; El-Danaf and Huberman, 2015), spontaneous and light-evoked responses (Holcombe et al., 2008; Frankfort et al., 2013; Chen et al., 2015; Pang et al., 2015; Tao et al., 2019) and membrane excitability (Risner et al., 2018). However, it is currently unclear whether these previously described changes contribute directly to RGC death, or whether other yet to be described changes are critical.

There has been a long-standing interest in the contribution of aberrant glutamate receptor expression to the underlying etiology of glaucoma (reviewed in Almasieh et al., 2012). While early studies focused on the contribution of highly $\mathrm{Ca}^{2+}$-permeable NMDA receptors, 
recent studies have focused on the role of $\mathrm{Ca}^{2+}$-permeable AMPA receptors (CP-AMPAR; Wang et al., 2014; Cueva Vargas et al., 2015; Wen et al., 2018). CP-AMPARs are upregulated at synapses in response to several pathological conditions such as ischemic insult (Liu et al., 2004; Noh et al., 2005; Kwak and Weiss, 2006), ALS (Kwak et al., 2010; Yamashita et al., 2013), Alzheimer's and Parkinson's disease (Kobylecki et al., 2010; Whitehead et al., 2017), and drug addiction (Shukla et al., 2017). Permeability to $\mathrm{Ca}^{2+}$ is determined by the absence or presence of the GluA2 subunit. This subunit contributes a positively charged arginine residue to the channel pore, preventing passage of $\mathrm{Ca}^{2+}$ and $\mathrm{Zn}^{2+}$ (Cull-Candy et al., 2006; Bowie, 2012). The presence of this arginine depends on the RNA editing enzyme ADAR2 (Lomeli et al., 1994; Higuchi et al., 2000; Horsch et al., 2011). In the unedited form of GluA2, neutral glutamine is expressed, allowing for $\mathrm{Ca}^{2+}$ permeation. Thus AMPARs are permeable to $\mathrm{Ca}^{2+}$ if they lack GluA2, or contain an unedited form of the subunit. In response to pathological conditions, it appears that AMPA receptors can be remodeled to increase $\mathrm{Ca}^{2+}$ permeability via either mechanism.

Under normal conditions, CP-AMPAR also plays important roles in the induction and maintenance of synaptic plasticity in several brain regions. In the cerebellum, where it was first described, high-frequency stimulation of presynaptic parallel fibers drives the rapid replacement of CP-AMPARs with $\mathrm{Ca}^{2+}$ impermeable AMPARs (CI-AMPAR). The initial event that triggers this plasticity is $\mathrm{Ca}^{2+}$ influx through the CP-AMPAR itself (Liu and Cull-Candy, 2000). Insertion of CP-AMPARs is a critical step in the consolidation of fear-driven memories (Clem and Huganir, 2010; Liu et al., 2010; Rao-Ruiz et al., 2011; Hong et al., 2013). One consequence of a switch from CI- to CP-AMPAR is a change in postsynaptic excitability (Savtchouk and Liu, 2011; Liu and Savtchouk, 2012), but local increases in $\mathrm{Ca}^{2+}$ via influx through CP-AMPARs may have other consequences as well. Here we show that 2 weeks of ocular hypertension (OHT) is sufficient to remodel AMPARs in $\alpha$ On and $\alpha$ transient Off, but not $\alpha$ sustained Off RGCs. Interestingly, amongst the alpha type RGCs, the Off transient type appears more susceptible to degeneration in OHT models than other types, although there is some subtype variability depending upon the parameters that are being measured (Della Santina and Ou, 2017). AMPARs displayed increased voltage-dependent block by spermine, consistent with increased CP-AMPARs expression (Bowie and Mayer, 1995; Donevan and Rogawski, 1995; Kamboj et al., 1995; Koh et al., 1995). The remodeling of AMPARs as a result of OHT was not observed in a mouse line in which the GluA2 editing was built-in using transgenic substitution of arginine for glutamine at the $\mathrm{Q} / \mathrm{R}$ site, suggesting that the remodeling is accomplished by reduced RNA editing of GluA2, rather than removal of the subunit.

We also find, using an optogenetic approach, that OHT decreases synaptic gain at bipolar to $\alpha$ On RGC synapse. Interestingly, a decrease in synaptic gain, most evident at low stimulus intensities, was observed previously in a variant of CP-AMPAR plasticity in which $\mathrm{Ca}^{2+}$ influx through NMDA receptors drives replacement of CI-AMPARs with CP-AMPARs in the same type of RGC (Jones et al., 2012). Thus two different experimental conditions, chronic elevation of ocular pressure, or acute NMDA receptor activation, converge onto the same cell type to elevate CP-AMPARs and decrease synaptic gain. We also find a functional link between the remodeling of AMPARs and decreased synaptic gain and present evidence consistent with the idea that CP-AMPARs provide a route of $\mathrm{Ca}^{2+}$ influx to activate a retrograde messenger that reduces transmitter release from the presynaptic bipolar cell. Increased expression of CP-AMPARs may be a strategy to reduce synaptic input onto compromised RGCs in response to stressful conditions such as $\mathrm{OHT}$.

\section{MATERIALS AND METHODS}

\section{Animals}

Mice of either sex were used in this study. Mice were obtained from The Jackson Laboratory. For experiments in dark-adapted retinas, $\mathrm{C} 57 \mathrm{Bl} / 6 \mathrm{j}$ was used. For identification of $\alpha$ RGCs, we crossed the Kcng4 $4^{\text {cre }}$ (029414) with a Td-Tomato Cre reporter line (Ai14). For channelrhodopsin2 (ChR2)mediated depolarization of Type 6 bipolar cells, we crossed CCK $^{\text {cre }}(012706)$ with a line that expressed ChR2 following cre-mediated excision of an upstream STOP sequence (Ai32). The ADARB1 ${ }^{-/-}$Gria2 $2^{\mathrm{R} / \mathrm{R}}$ mouse line (Adarb1 ${ }^{\text {tmlphs- }}$ Gria2 ${ }^{\text {tm } 1.1 p h s} / \mathrm{Mmnc}$ ) was obtained from the MMRRC (034679$\mathrm{UNC}$ ). These mice will be referred to as $\mathrm{GluA} 2^{\mathrm{R} / \mathrm{R}}$.

\section{Bead Injection}

All procedures were following the animal care guidelines for the University of Nebraska Medical Center Institutional and Animal Care Use Committee. Animals were anesthetized with isoflurane, pupils were dilated with $1 \%$ tropicamide ophthalmic solution (Bausch and Lomb), and anesthetic drops ( $0.5 \%$ proparacaine hydrochloride; Bausch and Lomb) were applied to one eye. The anterior chamber was injected with $10 \mu \mathrm{m}$ polystyrene microbeads (cat \#F8834, Invitrogen). The bead suspension was concentrated by centrifugation of $200 \mu \mathrm{l}$ of the solution followed by removal of $150 \mu \mathrm{l}$ supernatant. For the delivery of beads, glass tubing (type 7052, King Glass) was pulled to a diameter of $50 \mu \mathrm{m}$ using a vertical puller (Narishige). The pipet was type filled with $1-2 \mu l$ of hyaluronate (Provisc, Alcon) followed by $1-2 \mu l$ of bead solution. Injection of hyaluronate before removing the pipet sealed the entry hole of the pipet and prevented the efflux of the beads. Beads were ejected using a manual microsyringe pump (World Precision Instruments). Following the injection, the antibiotic ciprofloxacin was applied to the eye. Control retinas were either from uninjected or sham injected eyes. No statistical difference in results was observed between these two groups. IOP measurements were made in both eyes with the TonoLab tonometer beginning 1-2 days before bead injection and once every 3 days for 18 days after injection. IOP was measured in anesthetized animals.

\section{Preparation of the Retina}

For experiments that measured light responses, mice were dark-adapted overnight before killing them with $\mathrm{CO}_{2}$ inhalation 
followed by cervical dislocation. Retinas were isolated under dim red light and retinas were incubated in a solution containing collagenase and hyaluronidase dissolved in oxygenated $\left(95 \% \mathrm{O}_{2}\right.$ and $5 \% \mathrm{CO}_{2}$ ) Ames media (Sigma-Aldrich) at room temperature 15-30 min to aid in penetration of the inner limiting membrane (Schmidt and Kofuji, 2011). Retinas were then mounted in the recording chamber and held in place with a slice anchor (Warner Instruments) and perfused with Ames bubbled with $95 \% \mathrm{O}_{2}$ and $5 \% \mathrm{CO}_{2}$ at a rate of $4-6 \mathrm{ml} / \mathrm{min}$. For optogenetic and puffing experiments, mice were dark-adapted for $1 \mathrm{~h}$ before sacrifice, and all manipulations were carried out in room light.

\section{Imaging}

Ten micrometer Alexa488 Hydrazide (ThermoFisher; catalog \#A10436) and 0.5\% Neurobiotin (Vector Labs; catalog \#SP-1120) were added to the normal internal solution. After recording, retinas were fixed in $4 \%$ paraformaldehyde for $30 \mathrm{~min}$, washed in PBS three times, and then incubated in a blocking solution of $5 \%$ donkey serum, $1 \%$ Triton X-100 and 0.5\% DMSO in PBS for $1 \mathrm{~h}$ at room temperature. Retinas were then incubated in blocking solution and goat anti-ChAT primary antibody (1:100; Millipore Sigma, catalog \#AB144P) and Texas Red-conjugated streptavidin (Vector Labs; catalog \#SA-5006) for 5 days at $4^{\circ} \mathrm{C}$. Retinas were then rinsed $3 \times$ and incubated for $2 \mathrm{~h}$ in Texas red-conjugated donkey anti-rabbit secondary (1:100; ThermoFisher; catalog \#PA1-28662) at room temperature, washed $3 \times$ in PBS, and mounted with Slowfade antifade (ThermoFisher catalog \#S2828). Images were taken with a Nikon A1 confocal microscope with an oil immersion $63 \times$ objective. Image dimension was $512 \times 512$ pixels (pixel size: $0.41 \mu \mathrm{m}$ ). $\mathrm{Z}$ scan resolution was $1 \mu \mathrm{m}$. Images were compiled using Fiji (ImageJ) software.

\section{Patch-Clamp Recording}

The retina was viewed on a video monitor using infrared illumination and a CCD camera (COHU Electronics) mounted to an Olympus Bx51 microscope equipped with a waterimmersion $40 \times$ objective. In dark-adapted conditions, transient and sustained Off $\alpha$ RGCs were targeted based on their large ( $\sim 20 \mu \mathrm{m}$ ) somas, response to light, and the presence or absence of a T type $\mathrm{Ca}^{2+}$ current. For experiments using puffs of AMPA, a Kcng $4^{\text {cre }}$ : Ail 14 reporter line was used to identify $\alpha$ RGCs and further classification into subtypes were carried out by filling cells to visualize the depth of dendrites (On vs. Off) and measurement of a T type current (Off transient vs. Off sustained). Pipettes (tip resistance 5-7 M $2 ; 1.5 \mathrm{~mm} \mathrm{OD}$, WPI) were filled with a cesium gluconate solution containing the following (in $\mathrm{mM}$ ): $123 \mathrm{Cs}$ gluconate, $8 \mathrm{NaCl}, 1 \mathrm{CaCl}_{2}, 10 \mathrm{EGTA}, 10 \mathrm{HEPES}, 10$ glucose, 5 ATP, 0.01 Alexa 488 (puff and optogenetic experiments), and $100-500 \mu \mathrm{M}$ spermine $(\mathrm{pH} 7.4 ; 290 \mathrm{mOsm})$. To isolate the AMPAR-mediated EPSC, strychnine (1 $\mu \mathrm{M})$, picrotoxin $(100 \mu \mathrm{M})$, and D-AP5 $(50 \mu \mathrm{M})$ were added to Ames media. TPMPA $(50 \mu \mathrm{M})$ was included to blocked inhibitory feedback onto bipolar cells mediated by $\mathrm{GABA}_{\mathrm{C}}$ receptors. All chemicals were purchased from Sigma-Aldrich or Tocris Bioscience. Cells were voltage-clamped at $-60 \mathrm{mV}$. Current-voltage relations were obtained by stepping cells from $-60 \mathrm{mV}$ to $+80 \mathrm{mV}$ in $20 \mathrm{mV}$ increments. Cells were held at $0 \mathrm{mV}$ between steps. Holding potentials were corrected for a $12 \mathrm{mV}$ junction potential offline, and so voltages ranging from -72 to $+68 \mathrm{mV}$ are reported here. Series resistance, typically measuring 8-20 $\mathrm{M} \Omega$, was not compensated for. Recordings were discarded if series resistance was $>20 \mathrm{M} \Omega$. Recordings were obtained with an Axopatch 200B (Molecular Devices) using AxoGraph X acquisition software and digitized with an ITC-18 interface (Heka Instruments).

\section{Light Activation of AMPA Currents}

The light source for generating responses in the dark-adapted retina was a $20 \mathrm{~W}$ halogen lamp focused through a $40 \times$ objective. An interference filter (peak transmittance at $500 \mathrm{~nm}$ ) and neutral density filters were inserted in the light path to control the intensity and wavelength of light stimulation, and a shutter (Uniblitz; Vincent Associates) was used to control the duration of the stimulation, typically $1 \mathrm{~s}$. The intensity of the unattenuated light stimulus, measured using a ratiometric spectrophotometer (Thor Labs) was $4.9 \times 10^{5} \mathrm{R} * / \mathrm{rod} \cdot \mathrm{s}$ at $490 \mathrm{~nm}$, assuming a collecting area of $0.5 \mu \mathrm{M}$ per rod (Field and Rieke, 2002).

\section{Optogenetic Activation of AMPA Currents}

ChR2 was activated with a $1 \mathrm{~ms}$ activation of a $490 \mathrm{~nm}$ LED (Sutter Instruments). To measure responses over a range of type 6 bipolar cell membrane depolarizations, the voltage driving the led was regulated using a computer-controlled analog input to the LED. We used five voltages $(0.25 \mathrm{~V}, 0.5 \mathrm{~V}, 1 \mathrm{~V}, 2 \mathrm{~V}$, $2.5 \mathrm{~V})$. The LED intensity at each voltage, measured using a spectrophotometer (Thor Labs), was stable over the period over which these experiments were performed. To prevent photoreceptor inputs, L-AP4 $(10 \mu \mathrm{M})$ was included in the bath along with the standard antagonist cocktail.

\section{Activation of AMPA Currents With AMPA}

To apply AMPA we used a second pipet coupled to a positive pressure device (Picospritzer, Parker). For $\alpha$ On RGCs, the puffer pipet was positioned at the surface of the retina. For $\alpha$ Off RGCs, the puffer was advanced into the retina. Even before identification of cell type was confirmed anatomically, $\alpha$ On cells could be readily identified by the more rapid onset and decay of AMPA responses compared with Off $\alpha$ RGCs, whose dendrites ramify more deeply in the IPL. The continuous flow of Ames media from a locally positioned capillary tube (ID 200 $\mu \mathrm{m}$, Polymicro Technologies) dramatically increased the rate of diffusion of AMPA from the tissue following each puff. Hundred milliseconds Puffs of AMPA at a pressure of 2-3 psi were applied at 20-s intervals to ensure sufficient time for washout from the tissue.

\section{Experimental Design and Statistical Analysis}

The analysis was performed using AxoGraph $\mathrm{X}$ and KaleidaGraph (Synergy Software) software. The rectification index (RI) we calculated by first fitting the currents obtained at negative holding potentials with linear regression. The RI was the ratio of the amplitude of the current evoked at $+48 \mathrm{mV}$ was to the current amplitude at the same voltage predicted by the regression. We chose $+48 \mathrm{mV}$ rather than $+68 \mathrm{mV}$ as the test voltage, as some cells showed a reduced spermine block at 


\section{$\alpha$ Off Transient}
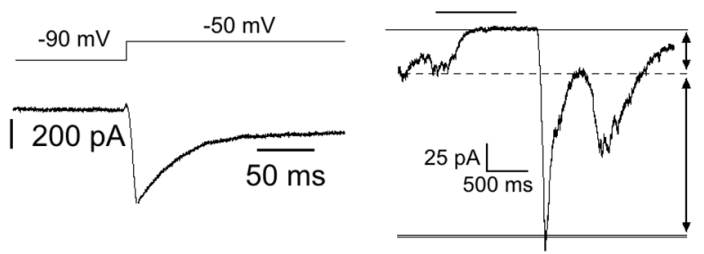

B

$\alpha$ Off Sustained
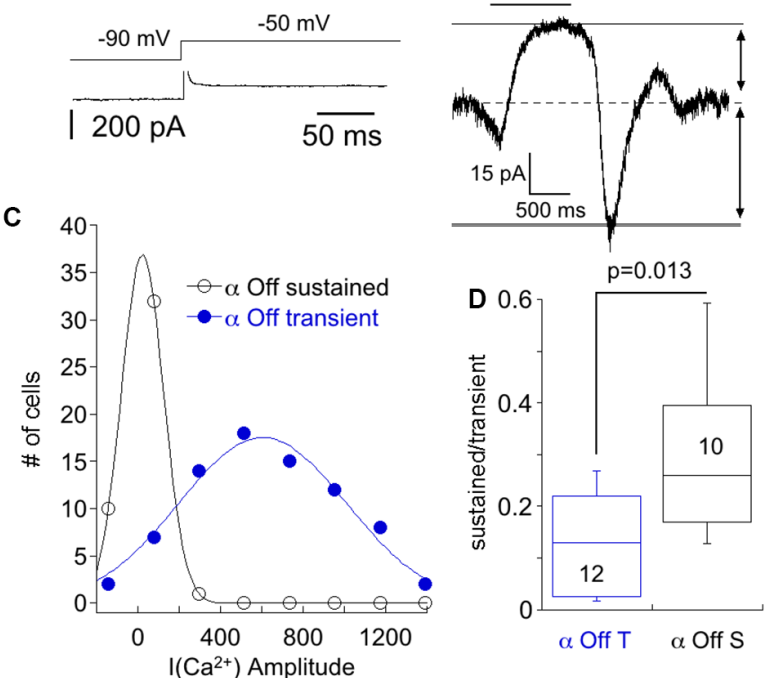

E

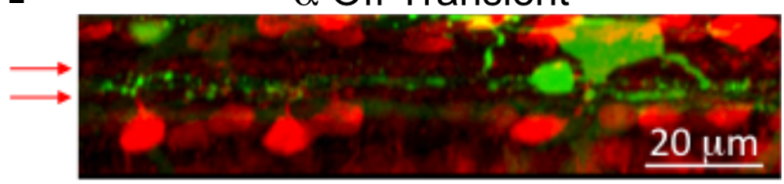

$\alpha$ Off Sustained

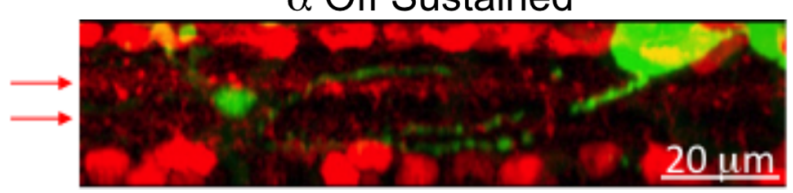

FIGURE 1 | Responses of $\alpha$ Off sustained and transient retinal ganglion cells (RGCs) to steps of dim light. (A) Left, $\mathrm{Ca}^{2+}$ current of an $\alpha$ Off sustained RGC evoked by voltage step from -90 to $-50 \mathrm{mV}$. Right, the response of the same cell to a 1 s $490 \mathrm{~nm}$ light delivering $6.8 \mathrm{R}^{\star} / \mathrm{rod}$. The light-suppressed continuous current is indicated by the thin and dashed lines, and the transient response at light off is bounded by the broken and thick solid line. (B) Example of the response to a voltage step from -90 to $-50 \mathrm{mV}$ (left) and the response to a light stimulus (right) in an $\alpha$ Off sustained RGC. Note that for the $\alpha$ Off sustained cell the current suppressed by light was larger, relative to the total current, than for the $\alpha$ Off transient RGC. (C) Histogram of $\mathrm{Ca}^{2+}$ current amplitudes for $\alpha$ Off transient and $\alpha$ Off sustained RGCs. Continuous lines are Gaussian fits with peaks at 604 pA and 23 pA, respectively. (D) Box plot summarizing the ratio of the sustained, light suppressed current to the transient current at light off for $\alpha$ Off transient and $\alpha$ Off sustained RGCs. (E) Side view of maximum intensity projection showing the soma and processes of an $\alpha$ Off transient (top) and $\alpha$ Off sustained (bottom) RGC filled with Neurobiotin (green) following electrophysiological characterization. Starburst amacrine cells are identified by ChAT labeling (red). Arrows indicate the position of ChAT bands. the more positive voltage (Bowie and Mayer, 1995). Statistical significance was determined using the Wilcoxon-Mann-Whitney test. Error bars indicate the SEM. Details regarding the number of cells for each condition can be found in the figure legends.

\section{RESULTS}

\section{$\alpha$ Transient and Sustained Off RGCs Express Predominantly $\mathrm{Ca}^{2+}$-Impermeant AMPARs in Normal Retina}

We first targeted $\alpha$ Off RGCs, identified by their large size, slightly oval shape, and characteristic light responses, as described below. Two classes of $\mu$ Off RGCs, the $\alpha$ Off transient RGCs and the $\alpha$ Off sustained could be distinguished using several criteria. The $\alpha$ Off transient RGC expressed a robust $\mathrm{T}$ type $\mathrm{Ca}^{2+}$ current (Figure 1A, left), as described previously (Margolis and Detwiler, 2007; van Wyk et al., 2009; Murphy and Rieke, 2011). The amplitude distribution of $\mathrm{T}$ type $\mathrm{Ca}^{2+}$ current that was measured in $\mu$ RGCs could be well fit with a single Gaussian, suggesting that the distribution describes a single population of cells (Figure 1C). $\alpha$ Off transient RGCs responded to termination of dim light (1 s stimulus of $490 \mathrm{~nm}$, the intensity of $\sim 0.7-7 \mathrm{Rh}^{\star} /$ rod) with a large inward current which rapidly decayed to a small sustained dark current, indicated by the dashed line (Figure 1A, right). Conversely, $\alpha$ Off sustained RGCs lacked $\mathrm{T}$ type $\mathrm{Ca}^{2+}$ currents (Figure 1B, left), and they typically had a larger sustained inward current in darkness compared with transient cells (Figure 1B, right), as might be expected if this ongoing excitatory input contributes to spike generation in darkness. Overall, the sustained synaptic current observed in darkness accounted for $29 \pm 5 \%$ of the total current evoked by the cessation of light. In contrast, the sustained dark current of $\alpha$ Off transient RGCs accounted for only $13 \pm 3 \%$ of the total current (Figure 1D). In some cells, identification of cell type was further confirmed by filling with Neurobiotin and examining the layer of termination of the dendrites. The dendrites of cells identified as $\alpha$ Off transient RGCs terminated in layers bounded on both sides by the processes of starburst amacrine cells (Figure 1E, top), while the dendrites of $\alpha$ Off sustained RGCs terminated in layers distal to the processes of Off starburst amacrine cells (Figure 1E, bottom) in agreement with previous studies (van Wyk et al., 2009; Bleckert et al., 2014).

We determined if CP-AMPARs contribute to synaptic transmission from bipolar cells in either $\alpha$ Off sustained or transient RGCs by measuring the IV relationship of the light response in both types of cells. NMDA receptors were blocked with D-APV $(50 \mu \mathrm{M})$, and feedforward inhibition was blocked with strychnine and picrotoxin to avoid contamination of the I-V relationship with non-AMPA currents. Spermine (100-500 $\mu \mathrm{M})$, which selectively blocks CP-AMPARs at positive, but not negative holding potentials (Bowie and Mayer, 1995; Kamboj et al., 1995; Koh et al., 1995), was included in the pipet solution. An example of the light response of an $\alpha$ transient Off RGC at three holding potentials is shown in Figure 2A. AMPA current was measured at the cessation of light (filled circle) when transmitter release from bipolar cells reaches a peak. 
If CP-AMPARs contribute to the light response, they should be open at negative voltages, but blocked at positive voltages, resulting in the inward rectification of the IV relation. However, this was not observed in RGCs taken from eyes with normal ocular pressure, as the amplitude of the light response was not diminished at positive voltages.

As a second method for estimating CP-AMPAR expression, we puffed AMPA onto the dendrites of RGCs. To confirm the identity of RGC cell type, we crossed Kcng $4^{\text {cre/cre }}$ mice with a line in which a floxed STOP cassette prevents transcription of Td-tomato (Ai9, Jackson labs). This line labels $\alpha$ RGCs, both On and Off types (Duan et al., 2015; Krieger et al., 2017), in addition to at least one population of the bipolar cell (Duan et al., 2014). We distinguished transient from sustained $\alpha$ Off RGCs by the presence of T type current as before. $\alpha$ Off cells could be distinguished from $\alpha$ On cells by the positioning of their dendrites, visualized by the inclusion of Alexa 488 to the pipet solution. Also, $\alpha$ On cells had faster and larger responses to AMPA than $\alpha$ Off cells, presumably due to the proximity of their dendrites to the surface of the retina and the puffer pipet. An exemplar IV relation of the AMPA puff response from an $\alpha$ Off transient cell is shown in Figure 2B. Inspection of the raw currents shows that, as for light-evoked currents, responses to AMPA did not rectify. The averaged currents generated by light-driven synaptic responses, or direct activation of receptors with AMPA, are plotted at eight different holding potentials in Figure 2C. The responses are essentially linear, as indicated by a rectification index near 1.0 (Figure 2C, inset; Light: $0.90 \pm 0.06$, $n=7$; AMPA puffs: $\mathrm{RI}=1.00 \pm 0.07, n=7$ ).

We obtained similar results when measuring the IV relations of both light and AMPA evoked currents in $\alpha$ sustained Off RGCs (Figures 2D,E). The amplitude of both types of responses was linear between holding potentials of -70 to $+70 \mathrm{mV}$. The rectification index measured using either light or puffs of AMPA, were not significantly different, and both approached unity (Figure 2F; $\mathrm{RI}_{\text {puff: }} 0.87 \pm 0.03, n=8$; $\mathrm{RI}_{\text {light }}: 0.94 \pm .01$, $n=5, p=0.22$ ). Taken together, it appears that endogenous and exogenous activation target the same, or largely overlapping AMPA receptor populations. In subsequent figures, data from both approaches are pooled.

\section{OHT Selectively Causes Remodeling of AMPARs in $\alpha$ Transient Off RGCs}

We wanted to determine if chronic ocular hypertension (OHT) contributes to a change in AMPAR expression in $\alpha$ RGCs. We first focused on $\alpha$ Off type cells, using light and AMPA in combination with intracellular spermine to probe for changes. Mice were injected with microspheres in one eye (Figure 3A), while the other eye was either sham injected, or uninjected, serving as a control. IOP of both eyes was subsequently monitored (see "Materials and Methods" section for details). A clear elevation in IOP was observed in the bead-injected eye $(\sim 25 \%$ increase vs. control eye, $p<0.0001)$, and persisted at day 18, the last time point that measurements were taken (Figure 3B). Experiments were carried out on eyes following 14-21 days of OHT. An example of responses to light (Figure 3C) and AMPA (Figure 3D) in $2 \alpha$ Off transient RGCs taken from the retina of a hypertensive eye are shown at three holding potentials. Note that the responses to both AMPA and light are significantly reduced at positive holding potentials. The full IV relations of AMPA current evoked by light or AMPA puffs for $\alpha$ Off transient RGCs from both normal and OHT eyes are plotted in Figure 3E. The rectification index for cells from normal eyes was $0.97 \pm 0.04(n=14)$ compared to $0.52 \pm 0.03$ in retinas from HT eyes $(n=13)$, a highly significant difference $(p<0.0001)$. Thus, $\alpha$ Off RGCs undergo a dramatic reorganization of synaptic AMPA receptors in response to 2-3 weeks of OHT.

We performed similar experiments on $\alpha$ Off sustained cells. Recordings from sustained cells were obtained side by side with transient cells, from the same retinas. In contrast to transient cells, $\alpha$ Off sustained RGCs showed no evidence for increased expression of CP-AMPARs; responses to both light and AMPA puffs were nearly identical in magnitude at negative and positive holding potentials (Figures $\mathbf{3 F}, \mathbf{G}$ ). The corresponding $\mathrm{I}-\mathrm{V}$ relation for pooled $\alpha$ Off sustained RGCs was linear in retinas from mice with OHT, just as in retinas with normal pressure (Figure $3 \mathrm{H}$; normal: RI $=0.91 \pm 0.06, n=13$; OHT: $\mathrm{RI}=0.83 \pm 0.05, n=10 ; p=0.39$ ). Thus both types of $\alpha$ Off cells express low levels of CP-AMPARs in normal retina, but transient Off RGCs selectively increase CP-AMPAR expression in response to elevated pressure.

\section{OHT Also Increases CP-AMPAR Expression in $\alpha$ On RGCs}

To probe for changes in AMPAR expression in $\alpha$ On RGCs driven by OHT, we activated AMPA receptors using two different strategies. As with $\alpha$ Off RGCs, we puffed AMPA directly onto the dendrites of $\alpha$ On RGCs. To activate receptors using endogenous synaptic input we made use of an optogenetic approach, crossing Cck-ires-cre mice to the Ai32 mouse line, which harbors ChR2 downstream from a floxed STOP cassette (Tien et al., 2017). This strategy confines expression of ChR2 to a single type of bipolar cell, cone bipolar type 6, which provides the majority of input to $\alpha$ On RGCs (Schwartz et al., 2012). To block the potential contribution of photoreceptor input to the optogenetic stimulation of type 6 bipolar cells, the mGluR6 agonist L-AP4 $(10 \mu \mathrm{M})$ was included in the bath along with D-APV, picrotoxin, and strychnine. Responses of two $\alpha$ On RGCs to either puffs of AMPA (Figure 4A, left) or $1 \mathrm{~ms}$ optogenetic stimulation of type 6 bipolar cells (Figure 4A, right), taken from eyes with normal IOP, are shown at three different holding potentials. Regardless of whether total AMPARs (using puffs of exogenous AMPA) or synaptic AMPARs (optogenetic stimulation) were examined, the amount of rectification was modest, indicating that CI-AMPARs were highly expressed at synaptic and extrasynaptic sites between type 6 bipolar cells and $\alpha$ On RGCs under normal conditions (Figure 4C, $\mathrm{RI}=0.70 \pm 0.03, n=24$ ).

Next, we determined whether OHT induced remodeling of AMPARs in $\alpha$ On RGCs. Following 2-3 weeks of elevated IOP, CP-AMPAR expression was evaluated by measuring I-V relations with spermine present in the pipet solution as before. 
A

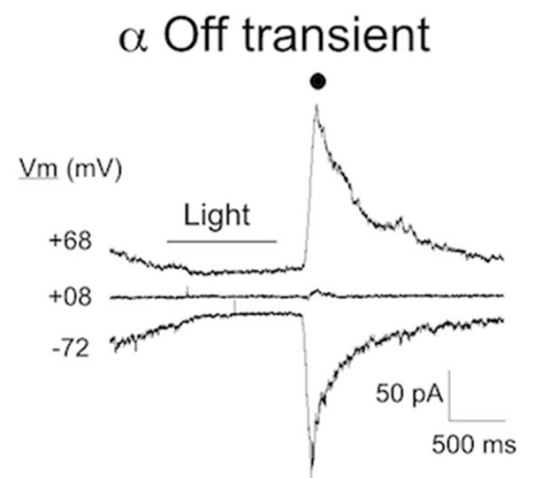

B

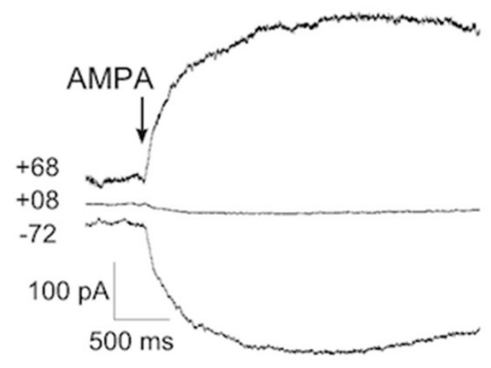

C

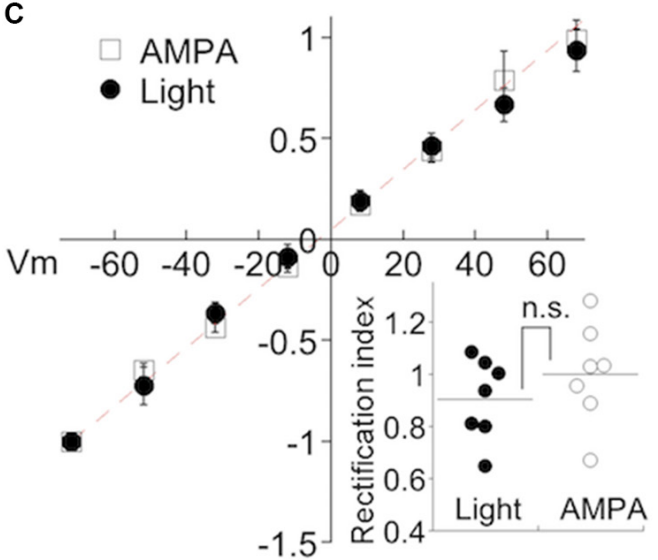

Normalized response
D $\quad \alpha$ Off sustained

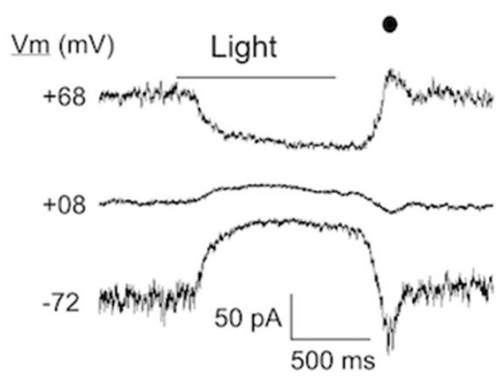

E

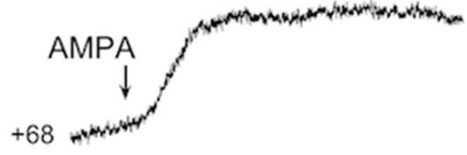

$+08$

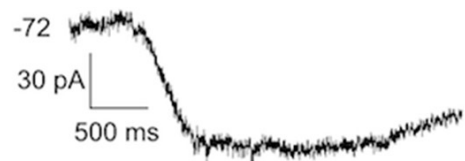

F

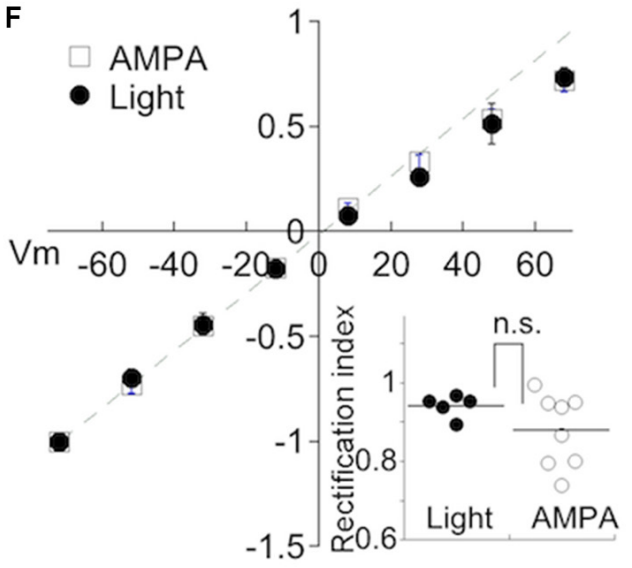

Normalized response

FIGURE 2 | $\alpha$ Off transient and sustained RGCs preferentially express $\mathrm{Ca}^{2+}$-permeable AMPA receptors (CP-AMPARs) under normal conditions. (A) The response of an $\alpha$ Off transient RGC to a $1 \mathrm{~s} 490 \mathrm{~nm}$ light delivering $6.8 \mathrm{R}^{*} /$ rod at three holding potentials. Spermine $(100-500 \mu \mathrm{M})$ is included in the pipet solution here and in all subsequent figures. A filled circle indicates the time at which the light-evoked current was measured for the IV relations. (B) The response of a different $\alpha$ Off transient cell to a 100 ms application of $100 \mu$ M AMPA. (C) Averaged IV relations of AMPA currents evoked with either light or exogenous AMPA. The dashed line indicates the linear fit to the current at negative holding potentials. Inset: The rectification index, calculated from the IV relations for each cell (see "Materials and Methods" section). The lack of significant rectification in the presence of intracellular spermine probed with either light or AMPA, suggests that few CP-AMPARs are expressed in eyes with normal ocular pressure. (D-F) Exemplar responses of $\alpha$ Off sustained RGCs to light and AMPA, and the normalized mean IV relations.

Responses to AMPA (Figure 4B, left) and EPSC amplitude (Figure 4B, right) were reduced at positive holding potentials, indicating a significant upregulation of CP-AMPARs. Increased expression of CP-AMPAR can be clearly seen in the IV relations comparing $\alpha$ On RGCs from normal and hypertensive eyes (Figure 4C). The change in RI was highly significant, indicating the robust insertion of CP-AMPAR (Figure 4D, OHT; $\mathrm{RI}=0.43 \pm 0.02, n=34, p<0.0001$ vs. control eyes). Thus,
AMPA receptor expression of both $\alpha$ On and $\alpha$ Off transient RGCs, but not $\alpha$ Off sustained RGCs, is altered by OHT.

\section{Editing of GluA2 Plays a Role in OHT-Dependent Remodeling of AMPARs}

Next, we investigated the mechanism by which OHT increased CP-AMPAR expression. One potential mechanism is the replacement of AMPA receptors that contain the GluA2 subunit 


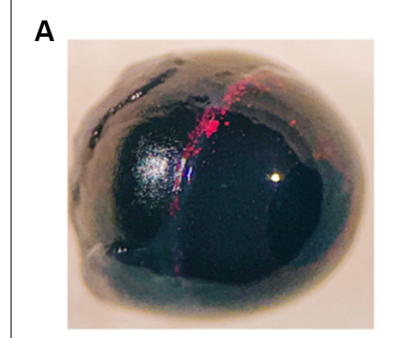

c $\alpha$ Off Tranisent RGC

Light response

$\mathrm{Vm}$

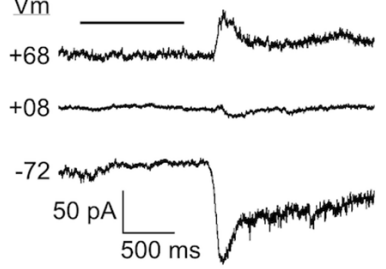

D AMPA puff response

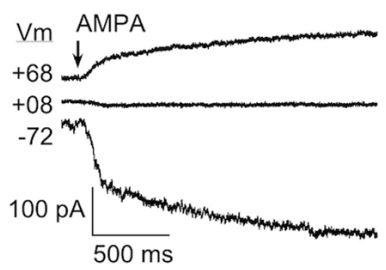

E

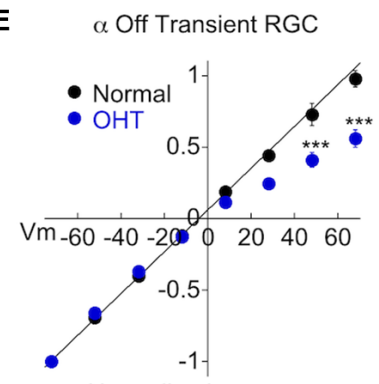

Normalized response

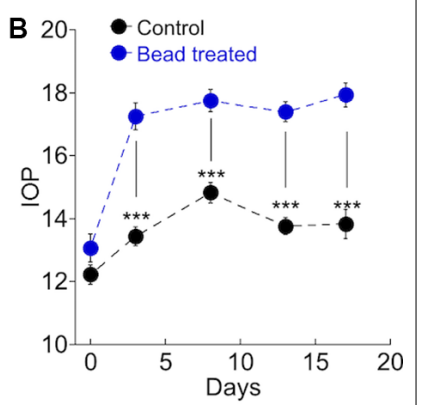

F $\quad \alpha$ Off Sustained RGC Light response

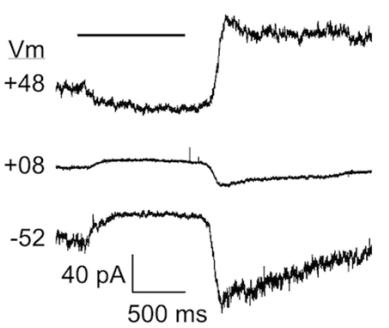

G AMPA puff response

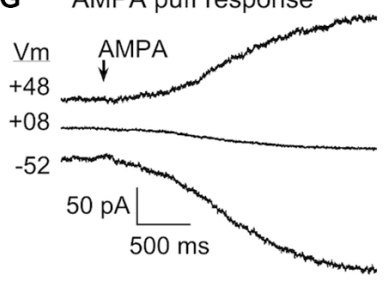

H

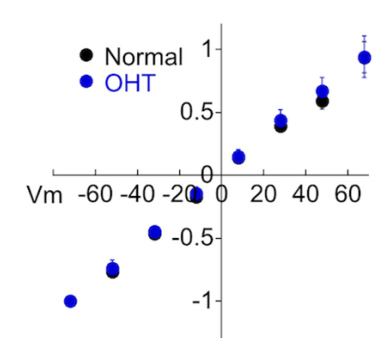

Normalized response

FIGURE 3 | Ocular hypertension (OHT) drives remodeling of AMPARs in $\alpha$ Off transient RGCs, but not $\alpha$ Off sustained RGCs. (A) Image confirming the presence of microbeads in the ciliary margin 2 weeks after microinjection of the eye. (B) Measurements of intraocular pressure (IOP) of bead injected and sham injected eyes (control). Data are binned as follows: Day 0, 1-2 days before bead injection; day 3, 2-5 days after bead injection; day 8, 7-10 days; day 13, 12-15 days; day 17, 16-19 days. (C) The light response of an $\alpha$ Off transient RGC at three holding potentials. The amplitude of the response at light Off is reduced at the positive voltage due to the voltage-dependent block of the CP-AMPAR component of the light response by spermine. (D) The response of another $\alpha$ Off transient RGC to AMPA at three holding potentials. The AMPA response is similarly reduced at positive voltage. (E) IV relations for $\alpha$ Off transient RGCs from retinas with normal pressure and with OHT. IV relations obtained using AMPA and light have been pooled for both control (data from Figure 2; $n=14$ ) and OHT retinas $(n=13)$. The difference was highly significant $\left({ }^{* \star *} p<0.0001\right)$. (F) The light response of an $\alpha$ Off sustained

(Continued)

FIGURE 3 | Continued

RGC from a hypertensive eye at three holding potentials. Responses at positive and negative holding potentials are equal in amplitude, despite the presence of spermine in the pipet solution, indicating a lack of CP-AMPAR expression. (G) Responses to the application of AMPA at positive and negative holding potentials are also of equal amplitude. (H) Pooled IV relations comparing $\alpha$ Off sustained RGCs from retinas with normal IOP (data from Figure 2; $n=13$ ) and $\mathrm{OHT}$ retinas $(n=11)$.

with receptors that do not. The second is a reduction in RNA editing of the $\mathrm{Q} / \mathrm{R}$ site in the pore-forming region of the GluA2 subunit, which would in turn reduce the editing of glutamine to the positively charged arginine that prevents $\mathrm{Ca}^{2+}$ from passing through the channel. To distinguish between these two possibilities, we examined the effect of hypertension in a double mutant mouse line in which the enzyme responsible for RNA editing of GluA2, ADAR2, has been knockout out (MMRRC; Adarb1:Gria2, here abbreviated $\mathrm{GluA}^{\mathrm{R} / \mathrm{R}}$ ). Since this is ordinarily a lethal mutation, a second mutation is a transgenic replacement of glutamine with arginine at the $\mathrm{Q} / \mathrm{R}$ site, ensuring that AMPARs containing the GluA2 subunit cannot be $\mathrm{Ca}^{2+}$ permeable even in the absence of editing by ADAR2 (Higuchi et al., 2000). The responses of two $\alpha$ Off transient RGCs to light (left) or AMPA puffs (right) from the double mutant mouse line following 2-3 weeks of OHT are shown in Figure 5A. Inspection of the raw data at positive and negative voltages shows a lack of inward rectification in either cell. Pooled I-V plots for $\alpha$ Off Transient RGCs from ocular hypertensive GluA2 ${ }^{\mathrm{R} / \mathrm{R}}$ mice are shown along with I-V plots from OHT mice with normal GluA2 function (from Figure 2) in Figure 5C. Rectification of the IV for $\alpha$ transient Off RGCs in GluA2 ${ }^{\mathrm{R} / \mathrm{R}}$ mice was nearly absent and was significantly different from bead treated mice with wildtype GluA2 (Figure 5E, $P<0.0001$ vs. OHT GluA2 $w t$ ), but not significantly different from mice with normal IOP $(p=0.265)$.

Genomic editing of GluA2 also reduced rectification in $\alpha$ On RGCs of OHT mice, but the effect was more subtle. AMPA-evoked responses were smaller at positive voltages than at negative voltages, indicating the presence of rectification (Figure 5B). However, the I-V relation of $\alpha$ On RGCs of GluA2 $^{\mathrm{R} / \mathrm{R}}$ mice with OHT rectified substantially less than the $\mathrm{I}-\mathrm{V}$ relation of $\alpha$ On RGCs from wildtype mice with OHT (Figure 5D, wildtype I-V replotted from Figure 4), and the difference in rectification between these two groups was highly significant (Figure 5E; GluA2 ${ }^{\mathrm{R} / \mathrm{R}} \mathrm{RI}=0.64 \pm 0.04, n=10$; wildtype $\mathrm{RI}=0.47 \pm 0.02, n=24 ; p=0.0006$ ). Furthermore, there was no significant difference in IV rectification between $\alpha$ On RGCs from GluA2 ${ }^{\mathrm{R} / \mathrm{R}}$ mice subjected to OHT and $\alpha$ On RGCs from wildtype GluA2 mice with normal eye pressure (Figure 5E; $p=0.84$ ). Thus, CP-AMPAR expression induced by OHT can be largely eliminated by preventing a decrease in GluA2 editing in $\alpha$ On RGCs. However, there remains an additional component of CP-AMPAR expression in $\alpha$ On RGCs which is resistant to the editing of GluA2 and is also present in retinas with normal IOP. It seems likely that this component of CP-AMPAR expression is contributed by GluA2 lacking AMPARs at type 6 BC- $\alpha$ On RGC synapses, and is present in $\alpha$ On but not $\alpha$ Off RGCs. 


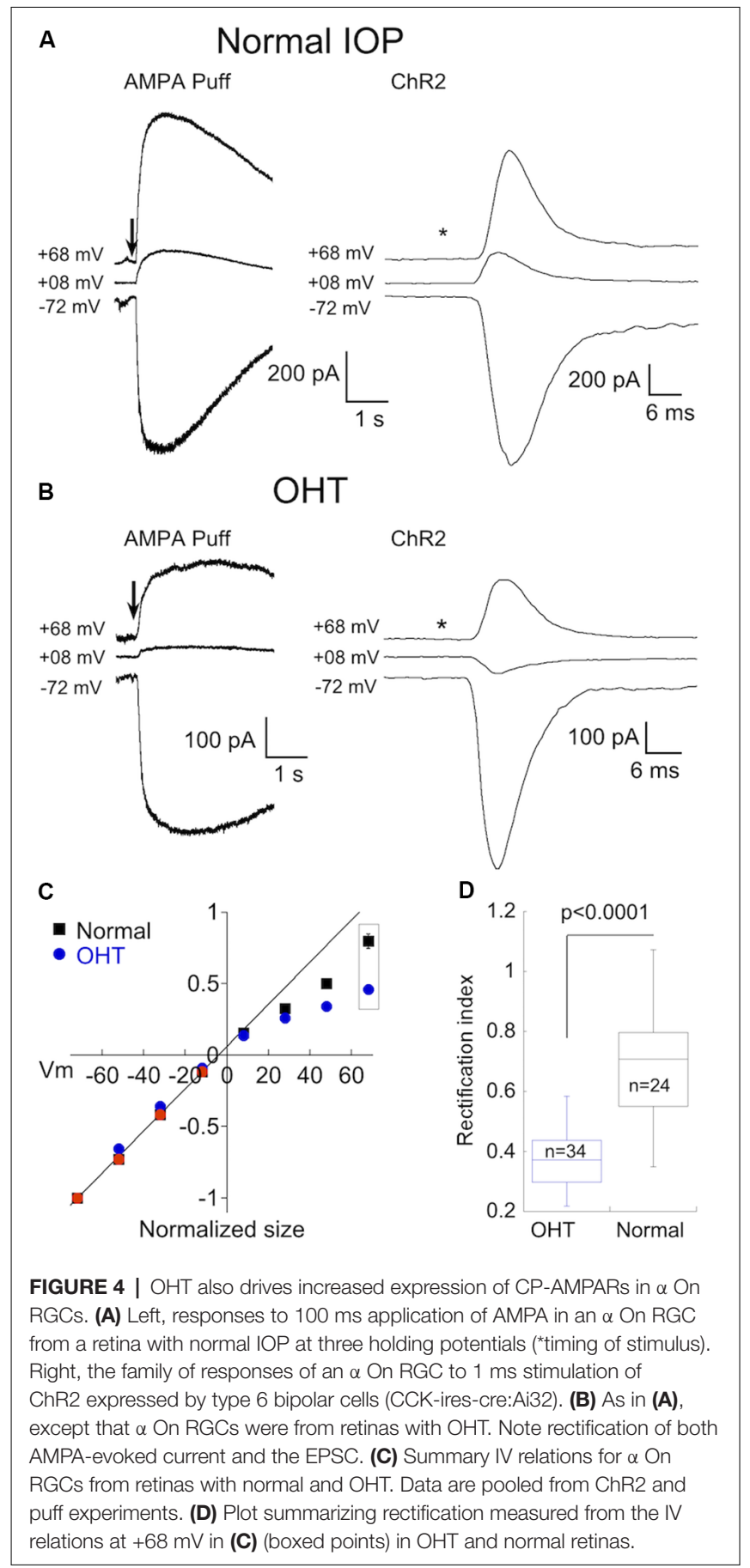

As expected, no differences in CP-AMPAR expression were observed in $\alpha$ Off sustained RGCs from GluA2 $2^{\mathrm{R} / \mathrm{R}}$ mice with elevated IOP compared with control mice with normal or elevated IOP.

\section{Elevation of CP-AMPAR Expression Is Associated With a Decrease in Gain at the Type 6 Bipolar- $\alpha$ RGC Synapse}

A decrease in the gain of light responses of $\alpha$ On RGCs has been reported following the elevation of IOP (Della Santina et al., 2013; Pang et al., 2015), but the mechanism or specific site responsible for the decrease has not been determined. Optogenetic stimulation of presynaptic type 6 bipolar cells allows us to ask if OHT functionally alters synaptic transmission between bipolar and $\alpha$ On ganglion cells. We stimulated type 6 bipolar cells in normal and OHT eyes, varying the voltage driving the LED to control the light intensity and subsequent bipolar cell type 6 depolarization, and recorded the resulting EPSCs in $\alpha$ On RGCs to generate an "intensity"-response function (Figure 6A). When the same light intensities were used to evoke EPSCs in $\alpha$ On RGCs from hypertensive eyes, responses were reduced or absent at lower stimulus intensities compared to normal retinas (Figure 6B). However, responses between the two groups were not significantly different at high stimulus intensities, in agreement with measurements of light-evoked AMPA currents in RGCs from hypertensive and normal eyes in a previous study (Risner et al., 2018). The relationship between the LED input voltage and $\alpha$ On EPSC was highly repeatable across cells from normal and OHT eyes, and a good fit to the response relationship for both conditions could be obtained using a standard Hill function (Figure 5D, control vs. OHT). Thus, OHT decreases synaptic gain at lower stimulus intensities, and increases CP-AMPAR expression at the type 6 bipolar- $\alpha$ On RGC synapse, raising the possibility that the two effects might be causally related.

To gain more insight into this possibility, we sought an alternative experimental model in which CP-AMPAR expression is increased in the absence of OHT. High-frequency stimulation of the bipolar- $\alpha$ On RGC synapse causes rapid insertion of CP-AMPARs through a mechanism that involves NMDARs (Jones et al., 2012). In the present study, experiments were carried out in room light, and D-APV was always present in the bath to block the insertion of CP-AMPARs. In the absence of the NMDAR antagonist, the rectification index was $0.45 \pm 0.03(n=35, p<0.0001$ compared to retinas treated with D-APV), indicating that room light alone is sufficient to cause substantial insertion of CP-AMPARs when NMDARs are not blocked. We, therefore, asked whether the synaptic gain was decreased at synapses where NMDARdependent plasticity had been induced. Similar to synapses from retinas with OHT, we observed a decrease in EPSC amplitude at low stimulus intensities (Figure 6C). The relationship between EPSC amplitude and stimulus intensity was similar when CP-AMPAR expression was elevated either by NMDARdependent plasticity or by OHT (Figure 6D). Both OHT and NMDAR plasticity raised the stimulus intensity required to evoke $50 \%$ of the maximum EPSC $\left(\mathrm{I}_{1 / 2}\right)$ compared to cells from retinas with normal IOP in the presence of D-APV (Figure 6E). To further quantify the relationship between CP-AMPAR expression and synaptic gain, we plotted the rectification index of each cell in all three groups vs. the reciprocal of $I_{1 / 2}$ (Figure $6 \mathrm{~F}$ ). Surprisingly, the relationship between these two parameters was highly correlated across groups $\left(\mathrm{R}^{2}=0.61, p=1.7 \times 10^{8}\right) ; \alpha$ On RGCs with high levels of CP-AMPAR expression had a lower synaptic gain, and this relationship was agnostic to the conditions the cell had experienced. These experiments support the idea that a decrease 
in light sensitivity associated with elevated ocular pressure is a consequence of CP-AMPAR expression at the type 6 bipolar- $\alpha$ On RGC synapse.

\section{Postsynaptic Manipulations of $\alpha$ On RGCs Can Alter Transmitter Release From Type 6 Bipolar Cells}

Changes in synaptic intensity can have a presynaptic or postsynaptic locus or both. To determine the site of OHT induced plasticity, we first measured the paired-pulse ratio (PPR) a standard method for assessing changes in release probability. Strong stimulus intensities, $\alpha$ On RGCs from retinas with normal IOP and low CP-AMPAR expression (Figure 7A, right) exhibited significant paired-pulse depression (PPD) at short intervals (50 ms, Figure 7A, left), indicating high release probability under these conditions. At longer intervals, depression decreased, likely due to the replenishment of released vesicles. The rate of recovery could be adequately fit by the sum of a fast $\left(\tau_{\text {fast }}=94 \mathrm{~ms}\right.$ ) and slow $\left(\tau_{\text {slow }}=2.8 \mathrm{~s}\right.$ ) exponential (Figure $7 \mathrm{C}$ ), similar to the kinetics of recovery from depletion at rod bipolar cell terminals (Singer and Diamond, 2006; Wan and Heidelberger, 2011), and at climbing fiber presynaptic terminals in the cerebellum (Dittman and Regehr, 1998).

We performed paired-pulse experiments on $\alpha$ On RGCs from OHT eyes with elevated CP-AMPAR expression (Figure 7B). At high stimulus intensities, PPD at an interval of $50 \mathrm{~ms}$ was similar for normal and $\mathrm{OHT}$ eyes. At this interval, the ratio of the second to first EPSC was $0.53 \pm 0.06$ for normal eyes, and $0.51 \pm 0.05$ for OHT eyes $(p=0.83)$, suggesting that the initial release probability at type 6 bipolar cells under both experimental conditions is essentially the same. When we examined the PPR at longer intervals, we obtained a surprising result: subsequent EPSCs were dramatically reduced compared with EPSCs at similar time intervals in normal retinas (compare responses indicated by arrows and insets). In normal retinas, the EPSC evoked at $200 \mathrm{~ms}$ recovered to $78 \pm 2 \%$ of the first EPSC, but only to $49 \pm 3 \%$ of the first EPSC in OHT eyes (Figure 7C, $P<0.0001$ ). The slowed time course of the recovery from PPD of $\alpha$ On RGCs in hypertensive eyes can be explained by the addition of a delayed component of EPSC suppression superimposed on the recovery of EPSC from vesicle depletion. The delay in EPSC suppression varied slightly from cell to cell but reached a peak at 150-250 after the initial stimulus (Figure 7C, inset). At an interval of $2 \mathrm{~s}$, the EPSC in OHT eyes was still significantly suppressed relative to control animals. This delayed suppression of the EPSC persisted in the presence of the $\mathrm{GABA}_{\mathrm{c}}$ antagonist TPMPA, ruling out inhibitory feedback from amacrine cells as a potential mechanism.

To quantify the relationship between this form of delayed synaptic depression and CP-AMPAR expression, we compared the PPR at $200 \mathrm{~ms}$ with the RI for each cell. We pooled cells from normal and OHT eyes, using only RI as a variable. The RI was strongly correlated with the PPR at $200 \mathrm{~ms}$ (Figure 7D, $\mathrm{R}^{2}=0.65$; $\left.p=2.0 \times 10^{-6}\right)$. Below we consider the possibility that the first stimulus and EPSC provide a trigger that leads to a subsequent rapid and brief suppression of excitatory transmission, perhaps via a retrograde signaling pathway. CP-AMPARs may play a role in this process by providing a route for $\mathrm{Ca}^{2+}$ entry into the postsynaptic cell to initiate the signaling pathway.

If $\mathrm{Ca}^{2+}$ plays a role in the initiation of a postsynaptic signal that is retrogradely communicated to type 6 bipolar cell terminals, then the inclusion of BAPTA in the pipet solution to rapidly buffer $\mathrm{Ca}^{2+}$ might reduce or eliminate this signal as has been shown elsewhere for retrograde signaling. In support of this idea, dialyzing $20 \mathrm{mM}$ BAPTA into $\alpha$ On RGCs with high CP-AMPAR expression (RI < 0.4 ) prevented delayed synaptic depression (Figure $\mathbf{8 A}$ ). The kinetics of recovery in these cells (Figure $8 \mathrm{C}, \mathrm{t}_{\text {fast }}=81 \mathrm{~ms}, \mathrm{t}_{\text {slow }}=2.0 \mathrm{~s}$ ) were similar to $\alpha$ On RGCs that had low CP-AMPAR expression (Figure 7). Retrograde signaling is often mediated by the release of endocannabinoids, which act on presynaptic CB1 receptors. To determine if $\mathrm{CB} 1$ receptors play a role in the delayed suppression of EPSCs observed at $\alpha$ On RGCs, we applied $2 \mu \mathrm{M}$ AM251, a CB1 antagonist, to the retina and measured the PPR. To ensure that AM251 had sufficient time to penetrate the tissue, and because washing out of AM251 is slow, the antagonist was continuously perfused into the retina, and cells with high CP-AMPAR expression were chosen. Incubation of retinas with AM-251 also prevented delayed EPSC suppression (Figure 8B). The kinetics of recovery from PPD were similar to cells recorded with BAPTA or cells with low CP-AMPAR expression $\left(t_{\text {fast }}=58 \mathrm{~ms}, t_{\text {slow }}=2.1 \mathrm{~s}\right)$. The difference in PPD at $200 \mathrm{~ms}$ between high CP-AMPAR expressing cells recorded with EGTA and those recorded with BAPTA in the pipet solution or with AM-251 in the bathing solution was significant (Figure 8D). Thus either strong buffering of $\mathrm{Ca}^{2+}$ or block of $\mathrm{CB} 1$ receptors eliminated the delayed suppression of EPSCs, leaving behind an exponential recovery from transmitter depletion that was similar to the recovery observed in $\alpha$ On RGCs with low expression of CP-AMPARs.

If the influx of $\mathrm{Ca}^{2+}$ through CP-AMPARs contributes to changes in release probability, then blockade of CP-AMPARs should increase release. To test this, we acutely blocked CP-AMPARs by dialyzing $\alpha$ On RGCs with spermine and recording EPSCs at positive voltages, and then measured PPD. We also measured PPD in the same cells at negative holding potentials, when CP-AMPARs were unblocked. Cells with high levels of synaptic CP-AMPARs, as determined by the rectification index, were chosen for the study. D-APV was always present to block NMDA currents, and so CI-AMPARs were the primary detectors of synaptic glutamate at positive voltage. At positive holding potentials, PPD was consistently greater than at negative holding potentials (Figures 8E,F), an indication that release probability from presynaptic bipolar cells was greater when postsynaptic CP-AMPARs were blocked. The difference between $\mathrm{PPD}$ at the two holding potentials was highly significant (Figure 8G, $N=13$, paired rank-sum test).

\section{DISCUSSION}

In this study, we show that elevation of IOP via injection of microbeads into the anterior chamber, a widely used experimental model for glaucoma (Sappington et al., 2010; ElDanaf and Huberman, 2015; Pang et al., 2015; Risner et al., 2018), 
A

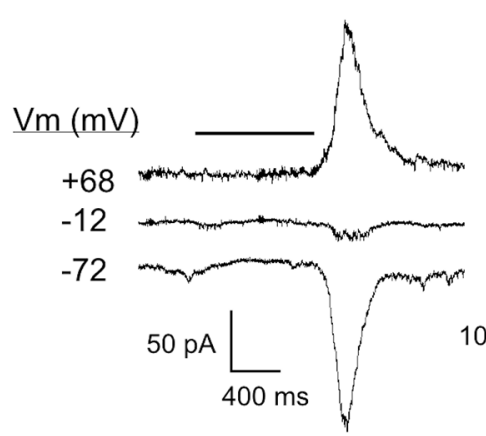

C $\alpha$ Off Transient

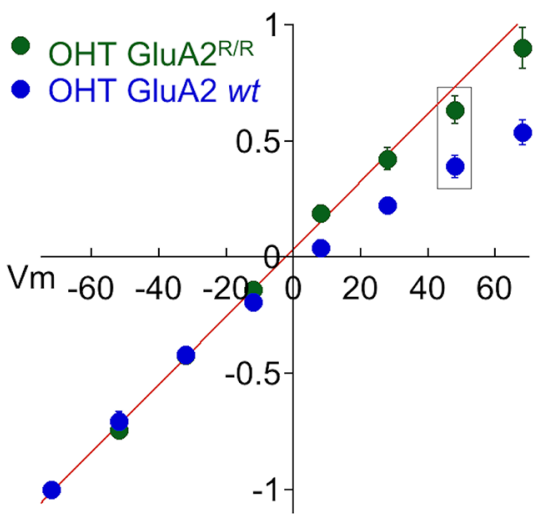

Normalized size

E $\alpha$ Off Transient

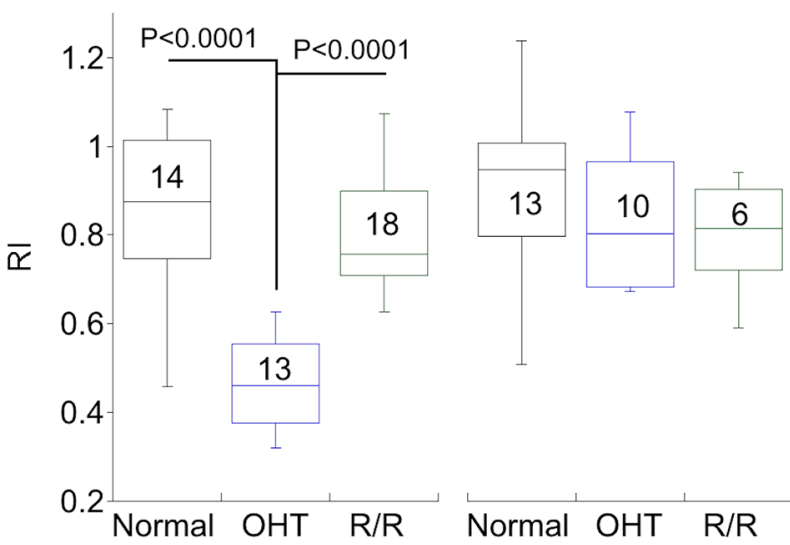

B

$\alpha \bigcirc n$
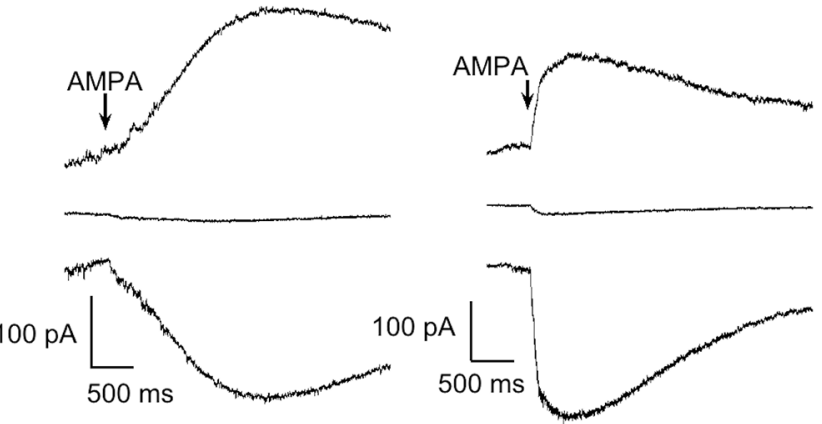

D

$\alpha$ On

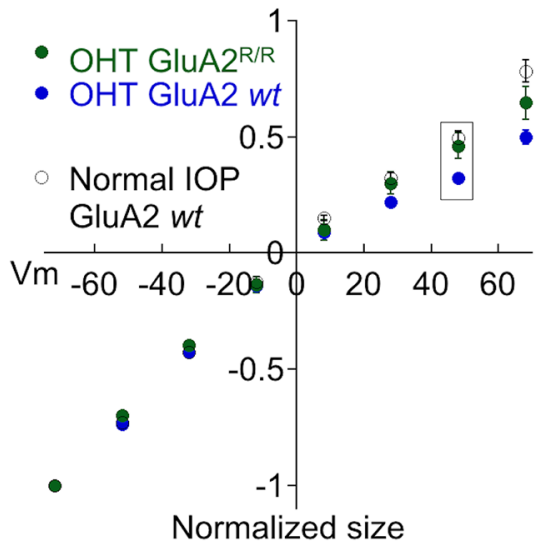

$\alpha$ On

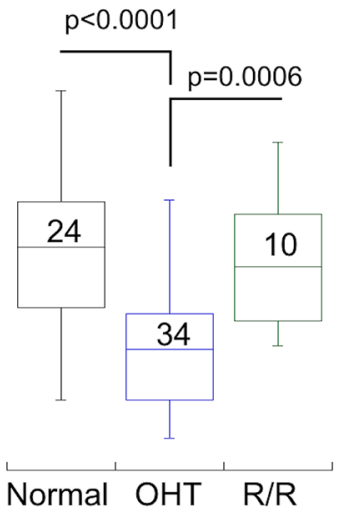

FIGURE 5 | Genomic editing of the GluA2 Q/R site prevents remodeling of $\alpha$ On and transient Off RGCs by OHT. (A) Recordings from two $\alpha$ Off transient RGC from the $A D A R 2^{-/-}$:GluA2 $2^{R / R}$ mouse line, one showing responses to light (left) and the other showing responses to puffs of AMPA (right) at three holding potentials. Retinas were from OHT eyes. (B) Responses to AMPA in an a On RGC from the same mouse line, also with OHT. (C) Mean IV relationship of $\alpha$ Off transient RGCs for $\mathrm{OHT}$ retinas from wildtype mice (data replotted from Figure 3 ) and ADAR2 ${ }^{-/-}:$GluA2 ${ }^{R / R}$ mice. The IV relations of $\alpha$ Off transient RGCs from mice with genomic editing of the Q/R site were linear, indicating a lack of CP-AMPAR expression. (D) Mean IV relationship of $\alpha$ Off transient RGCs for OHT retinas from wildtype mice (data replotted from Figure 4) and ADAR2 ${ }^{-1-}:$ GluA2 ${ }^{R / R}$ mice. Also shown is the mean IV relation for wildtype mice with normal IOP. Genomic editing of the Q/R site linearized the IV relation of $\alpha$ On RGCs with OHT to nearly the same degree as cells from retinas with normal IOP. (E) Summary rectification indices for all three $\alpha$ RGC types from normal and OHT retinas, and ADAR2 ${ }^{-1-}$ : GluA2 $2^{R / R}$ mice with OHT. In both $\alpha$ transient Off and $\alpha$ On RGCs, the effect of OHT on CP-AMPAR expression was reversed or reduced in the ADAR2 ${ }^{-1-}$ : GluA2 ${ }^{R / R}$ mouse. For $\alpha$ sustained Off RGCs there was no significant difference between any condition. 

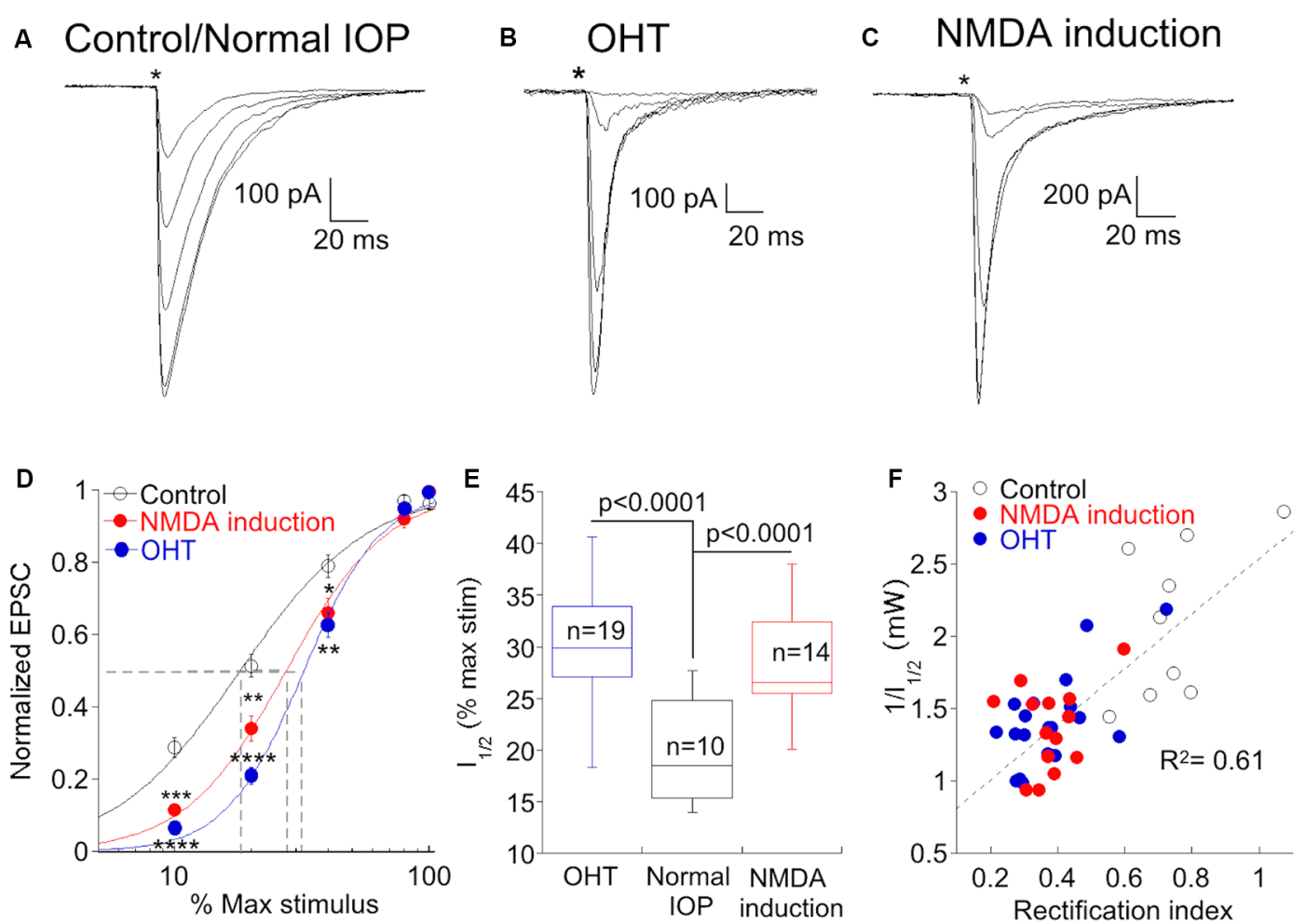

FIGURE 6 | An increase in CP-AMPAR expression is associated with a decrease in synaptic gain at low stimulus intensities. (A) Family of responses to a series of stimulus intensities in an $\alpha$ On RGC from a retina with normal IOP. The NMDA antagonist D-APV was present throughout the experiment to prevent NMDAR-dependent CP-AMPAR plasticity. (B) The response of an $\alpha$ On RGC from an OHT retina to the same series of stimulus intensities. Responses are typical for $\alpha$ On RGCs from this condition as the response to weak stimuli are reduced or absent, compared with cells from retinas with normal IOP. (C) Family of responses of an $\alpha$ On RGC from a retina with normal IOP, except that D-APV was present only during response measurements but not at other times. Under these conditions, RGCs showed a loss of sensitivity at low stimulus intensities. (D) Pooled data showing the normalized EPSC at each stimulus intensity under all three conditions. Fits are to the Hill equation with the following parameters: Control, slope $=1.7$, halfmax intensity $=18 \%$ of maximum stimulus; NMDA induction, slope $=2.2$, halfmax intensity $=27 \%$ of maximum stimulus; $\mathrm{OHT}$ slope $=2.8$, halfmax intensity $=32 \%$ of the maximum stimulus. Asterisks indicate significance for NMDA induction (upper asterisks) and $\mathrm{OHT}$ (lower asterisks) compared to control and are as follows: ${ }^{\star \star \star *} p<0.0001,{ }^{* \star *} p=0.0001,{ }^{* \star} p=0.006,{ }^{*} p=0.04$. $100 \%$ stimulus intensity was $4.01 \mathrm{~mW}$. (E) Box plot of the ChR2 stimulus intensity required to produce a half-maximal response in cells from normal eyes, normal eyes following induction of NMDAR plasticity, and hypertensive eyes. (F) Correlation of synaptic gain, measured as the reciprocal of the half-maximum intensity stimulus intensity, and CP-AMPAR expression, measured as the rectification index. Cells from all three conditions are indicated by separate symbols but are treated as a single population for calculation of the linear regression.

leads to upregulation of CP-AMPARs in RGCs. This form of AMPAR remodeling is cell-type specific, completely absent in $\alpha$ Off sustained RGCs, robust in $\alpha$ Off transient RGCs, and more modest in $\alpha$ On RGCs. Furthermore, we find that the remodeling of AMPARs is absent in RGCs from mice in which the Q/R site is genetically altered to arginine. This finding supports the idea that a reduction in editing by $A D A R 2$ at the $Q / R$ site is responsible for the increase in CP-AMPAR expression associated with chronic OHT. Robust AMPAR remodeling of $\alpha$ transient Off RGCs observed in the present study is in line with the notion that this cell type is particularly susceptible to OHT (Della Santina and $\mathrm{Ou}, 2017)$. Within the first 7 days, $\alpha$ transient Off RGCs undergo extensive dendritic pruning and loss of synaptic contacts, judged by a reduction in PSD-95 puncta (Della Santina et al., 2013; El-Danaf and Huberman, 2015; Ou et al., 2016). Physiological changes in parameters such as stimulus-evoked spike frequency, response sensitivity receptive field size, spontaneous activity, and excitability have been documented for $\alpha$ transient Off RGCs
(Della Santina et al., 2013; Pang et al., 2015; Ou et al., 2016; Risner et al., 2018) and they are observed before changes in structure. The finding that CP-AMPARs are upregulated during the same period raises the possibility that $\mathrm{Ca}^{2+}$ influx through abnormally high levels of these receptors plays a role in the degradation of dendrites.

\section{Is Remodeling of AMPAR a Consequence of Low Expression of ADAR2 or Downregulation of GluA2?}

Remodeling of AMPARs is a well-established consequence of a wide spectrum of neuronal dysfunction, including drug dependence (Wolf, 2016), seizures (Rakhade et al., 2008; Lippman-Bell et al., 2016), and ischemia (Noh et al., 2005; Dias et al., 2013; Hwang et al., 2013). While the evidence for increased expression of CP-AMPAR is often clear, the underlying mechanism, either a decrease in ADAR2 levels and consequently a decrease in GluA2 editing, or the alternative, exclusion of 


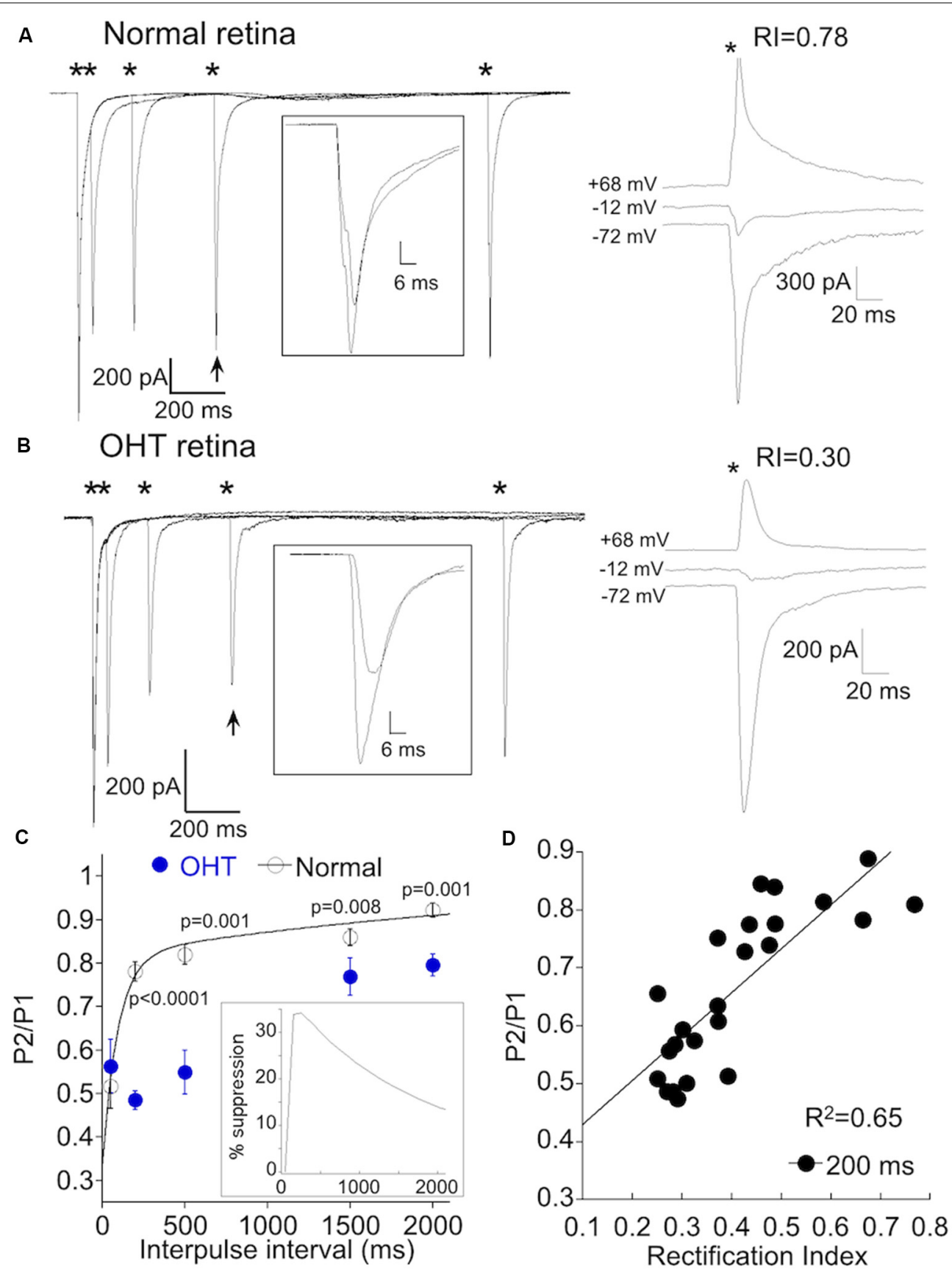

FIGURE 7 | AMPAR remodeling is associated with delayed short-term synaptic depression. (A) Left, responses of an $\alpha$ On RGCs from a retina with normal IOP to paired $1 \mathrm{~ms}, 8.0 \mathrm{~mW}$ ChR2 stimulation at intervals indicated by the asterisks. Inset: overlay of the first response with the response obtained 500 ms later (indicated by arrow). The recovery of the EPSC is nearly complete after $500 \mathrm{~ms}$. Right, IV relation of the same cell shows only a small amount of rectification, indicating low CP-AMPAR expression. (B) As in (A), but the $\alpha$ On RGC was from an OHT retina. Rectification at positive voltage is pronounced in this cell. Inset shows a reduced recovery of the EPSC at this time point. (C) Summary of paired-pulse depression (PPD) at the indicated pulse intervals of $\alpha$ RGCs from OHT ( $n=17$ ) and normal retinas $(n=14)$. The sum of two exponentials, $A_{\text {fast }}^{*} \exp \left(-t / t_{\text {fast }}\right)$ and Aslow*exp(-t/tslow $)$, was used to fit the recovery of the EPSC for $\alpha$ RGCs from retinas with normal IOP. The fits were extrapolated to $15 \mathrm{~s}$ following the first stimulus, which represented a full recovery of the EPSC. Inset: time course of the delayed suppression of the EPSC obtained from the difference of the mean fits the normal and OHT conditions. (D) Correlation of rectification index with the paired-pulse ratio (PPR) at 200 ms. The delayed PPR was highly correlated with CP-AMPAR expression $\left(p=2.0 \times 10^{-6}\right)$.

the GluA2 subunit in newly synthesized AMPARs, is less clear. Ultimately an understanding of the underlying mechanism has implications for treatment strategies. Downregulation of
ADAR2 and subsequent increases in CP-AMPARs has been identified as a key step in the progression of motor neuron loss in ALS (Kwak and Kawahara, 2005; Hideyama et al., 2012; 
A

\section{BAPTA}

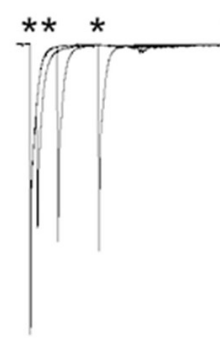

C

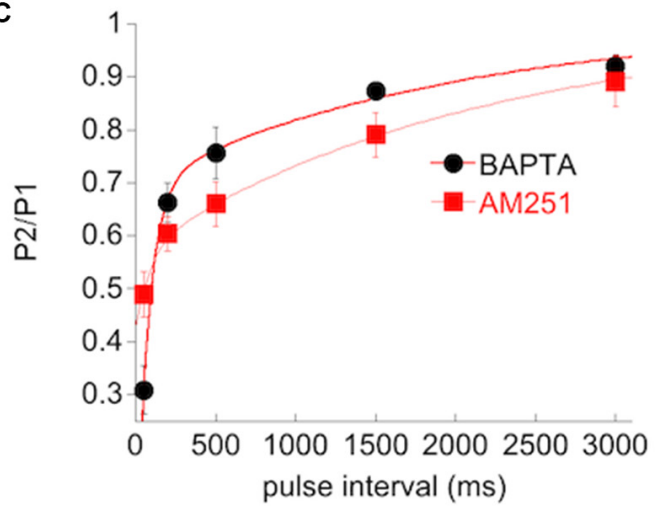

B

AM251
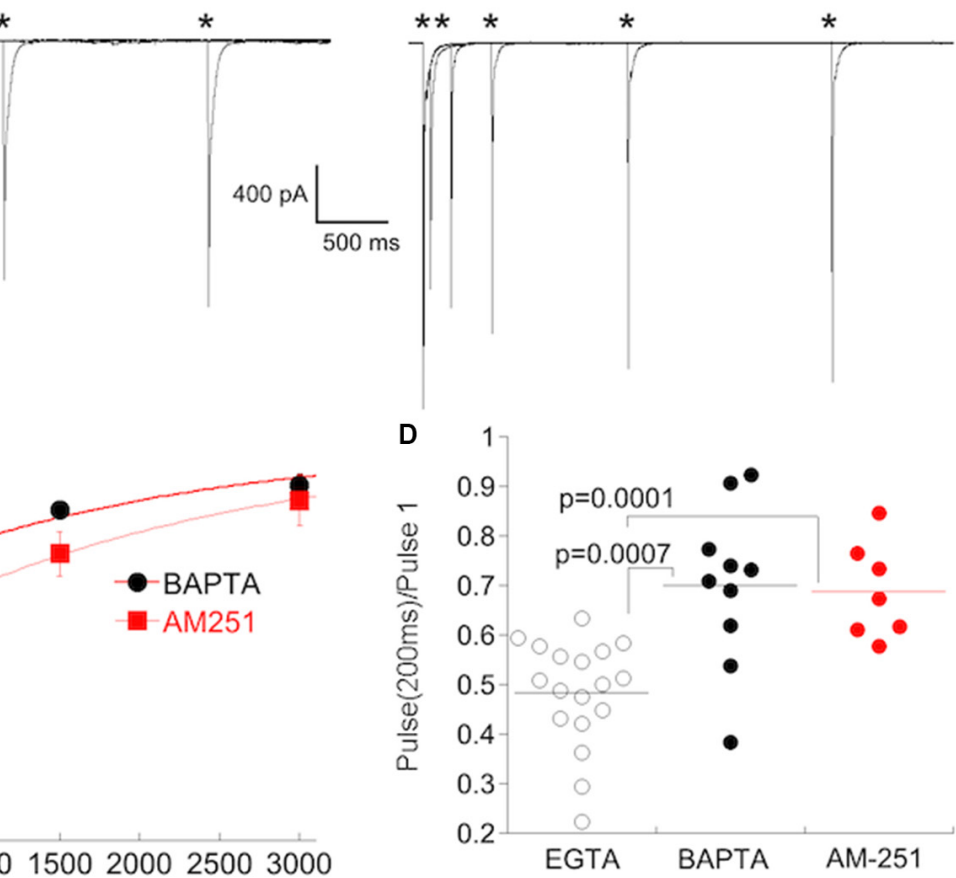

E

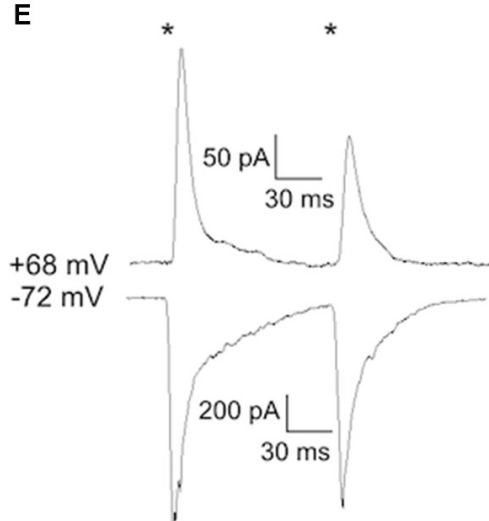

F

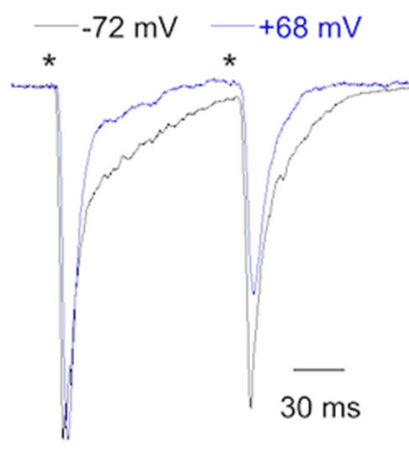

G

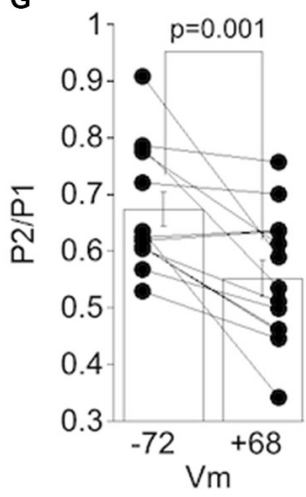

FIGURE 8 | Postsynaptic buffering of $\mathrm{Ca}^{2+}$ or blocking CB1 receptors abolishes synaptic depression at CBC6 to $\alpha$ On RGC synapse. (A) Responses from an $\alpha$ On RGCs to paired, 1 ms stimuli at the stimulus intervals ("timing of stimulus). The internal solution contained 20 mM BAPTA. (B) Responses of an $\alpha$ On RGCs to paired, $1 \mathrm{~ms}$ stimuli as in (A) with $2 \mu \mathrm{M}$ AM251 added to the bathing solution. Summary plot of the PPR under the conditions shown in (A,B). Cells recorded with the internal solution containing BAPTA and AM251 are from the retina with normal IOP but were induced to undergo NMDA-dependent plasticity by omitting D-APV. Only $\alpha$ On RGCs that displayed significant rectification [rectification index $(\mathrm{RI})<0.4$ ] were included for analysis. (C) Time course of recovery from PPD in $\alpha$ On RGCs recorded with BAPTA in the pipet solution, or with EGTA in the pipet and AM251 in the bath. PPD decreased monotonically, with no evidence of a delayed increase in depression despite significant expression of CP-AMPARs in these cells. (D) Statistical comparison of PPR at an interval of 200 ms in cells recorded with EGTA (a group of $\alpha$ On RGCs from Figure 7C), BAPTA, or with AM-251 in the bath. (E) Recordings showing paired-pulse responses (interval of $100 \mathrm{~ms}$ ) from an $\alpha$ On RGC at the indicated voltages. The stimulus intensity was reduced five fold from the intensity used for paired-pulse recordings presented previously. (F) Recordings from (E) scaled to show the increase in PPD at positive voltage. (G) Population data from $\alpha$ On RGCs $(n=13)$ timing of stimulus.

Lorenzini et al., 2018; Yamashita and Kwak, 2019). Furthermore, the deletion of ADAR2 in motor neurons is sufficient to phenocopy ALS and can be rescued by genomic editing of the $\mathrm{Q} / \mathrm{R}$ site (Hideyama et al., 2010). To establish a causal role in glaucoma, it would be instructive to determine whether the structural and functional losses associated with OHT are rescued in the GluA2 $2^{\mathrm{R} / \mathrm{R}}$ mouse line, where AMPAR remodeling is not observed.

OHT has also been shown to increase CP-AMPAR in RGCs of rat retina through mechanisms involving TNF- $\alpha$ (Cueva Vargas 
et al., 2015) and the EphB/EphrinB pathways (Dong et al., 2015). In both studies, The increased CP-AMPAR expression appeared to be associated with the down-regulation of GluA2, rather than altering ADAR2 editing. In the former study, the authors reduced outflow through the episcleral veins, resulting in an increase in IOP that was 2-fold higher than the IOPs achieved in the present study. Perhaps a larger increase in IOP recruits additional mechanisms of AMPAR remodeling. Furthermore, the authors of that study did not identify the affected RGC subtypes, leaving open the possibility that $\mathrm{OHT}$ activates different mechanisms of AMPAR remodeling, depending upon the specific RGC subtype.

In contrast to maladaptive CP-AMPAR expression under pathological conditions, adaptive changes in CP-AMPAR expression are an essential component of many forms of long and short-term plasticity that involve recruitment of existing or newly synthesized GluA2-lacking receptors (Ju et al., 2004; Clem and Barth, 2006; Sutton et al., 2006). In $\alpha$ On RGCs, a rapid NMDA-dependent increase in CP-AMPAR expression has been described previously (Jones et al., 2012) and was revealed in the present study by comparing CP-AMPAR expression in separate populations of $\alpha$ On RGCs either in the presence or absence of NMDAR blockers. Even under conditions of NMDAR block, $\alpha$ On RGCs expressed significant levels of CP-AMPARs, perhaps in response to lack of synaptic activity, a form of synaptic scaling described at several synapses (Isaac et al., 2007), including this one (Xia et al., 2007). This component of CP-AMPAR expression was spared in the GluA2 $2^{\mathrm{R} / \mathrm{R}}$ mouse, implying that it does not result from a decrease in GluA2 editing. Thus, it appears that both known mechanisms of AMPAR remodeling converge onto $\alpha$ On RGCs, one as a result of pathological OHT, the other due to a physiologically relevant stimulus.

\section{A Decrease in Synaptic Gain Is Associated With Elevated CP-AMPAR Expression}

The observation that both NMDA-dependent plasticity and OHT reduced synaptic gain in $\alpha$ On RGCs led us to investigate the possibility that CP-AMPAR expression and gain were linked. To drive synaptic input to $\alpha$ On RGCs, we used an optogenetic approach. This eliminates the confounding effects of OHT on upstream circuit elements. It also provides higher temporal resolution than other approaches, The ChR2-EGFP fusion protein was expressed in type 6 bipolar cell, which provides the majority of input to $\alpha$ On RGCs (Schwartz et al., 2012; Tien et al., 2017), while $\alpha$ Off RGCs appear to receive input from different cohorts of bipolar cells (Yu et al., 2018), allowing for only a minority of synaptic inputs to be stimulated optogenetically. We examined the relationship between the intensity of the stimulus driving ChR2 and the EPSC (Najac and Raman, 2017), and found this relationship to be quite repeatable across cells. One reason for this might be the high degree of convergence of synaptic connections from CB6 input onto individual $\alpha$ On RGCs (Freed et al., 1992; Kerschensteiner et al., 2009; Morgan et al., 2011; Schwartz et al., 2012), allowing for the smoothing of variability in ChR2 expression between bipolar cells.

The delayed suppression of EPSCs that we observed in $\mathrm{OHT}$ and NMDA-treated retinas shares some properties of depolarization-induced suppression of inhibition (DSI; Pitler and Alger, 1992, 1994) and depolarization-induced suppression of excitation (DSE; Kreitzer and Regehr, 2001a). Both DSI and DSE transiently suppress synaptic transmission with a short latency following depolarization. Suppression is due to the retrograde release of endogenous cannabinoids which bind to presynaptic CB1 cannabinoid receptors to reduce $\mathrm{Ca}^{2+}$ influx into synaptic terminals (Kreitzer and Regehr, 2001b; Wilson and Nicoll, 2001; Ohno-Shosaku et al., 2002; Chevaleyre and Castillo, 2004). The release is stimulated by a rise in postsynaptic $\mathrm{Ca}^{2+}$ through voltage-gated channels. In the present study, depression was initiated by a single stimulation of transmitter release, rather than postsynaptic depolarization, raising the possibility that $\mathrm{Ca}^{2+}$ influx through open CP-AMPARs is sufficient to turn on production of a retrograde messenger such as $2-\mathrm{AG}$ or anandamide, endogenous activators of CB1 receptors (Piomelli, 2003). Local increases in $\mathrm{Ca}^{2+}$ generated by influx through CP-AMPARs is sufficient to stimulate transmitter release from A17 amacrine cells in the absence of voltage-gated $\mathrm{Ca}^{2+}$ channels (Chávez et al., 2006), and stimulation of CP-AMPARs at mossy fiber-CA3 interneuron synapses initiates a presynaptic form of LTD (Lei and McBain, 2004). CB1 receptors are expressed in the inner retina in several species (Straiker et al., 1999; Yazulla et al., 1999), and cannabinoids have been shown to modulate synaptic input to RGCs (Middleton and Protti, 2011) and decrease $\mathrm{Ca}^{2+}$ currents in presynaptic bipolar cells (Straiker et al., 1999).

\section{DATA AVAILABILITY STATEMENT}

The raw data supporting the conclusions of this article will be made available by the authors, without undue reservation.

\section{ETHICS STATEMENT}

The animal study was reviewed and approved by Nebraska Medical Center Institutional Animal Care and Use Committee.

\section{AUTHOR CONTRIBUTIONS}

AS performed experiments and helped write the manuscript. SN designed experiments, analyzed data, made figures, and wrote the manuscript.

\section{FUNDING}

Funding was provided by the Department of Ophthalmology and Visual Sciences at the University of Nebraska Medical Center.

\section{ACKNOWLEDGMENTS}

We thank Dr. Wallace Thoreson for valuable discussions and critical reading of the manuscript, and Cody Barta for technical assistance. This manuscript has been released as a pre-print at bioRxiv (Sladek and Nawy, 2019). 


\section{REFERENCES}

Almasieh, M., Wilson, A. M., Morquette, B., Cueva Vargas, J. L., and Di Polo, A. (2012). The molecular basis of retinal ganglion cell death in glaucoma. Prog. Retin. Eye Res. 31, 152-181. doi: 10.1016/j.preteyeres.2011.11.002

Bleckert, A., Schwartz, G. W., Turner, M. H., Rieke, F., and Wong, R. O. (2014). Visual space is represented by nonmatching topographies of distinct mouse retinal ganglion cell types. Curr. Biol. 24, 310-315. doi: 10.1016/j.cub.2013.12. 020

Bowie, D. (2012). Redefining the classification of AMPA-selective ionotropic glutamate receptors. J. Physiol. 590, 49-61. doi: 10.1113/jphysiol.2011. 221689

Bowie, D., and Mayer, M. L. (1995). Inward rectification of both AMPA and kainate subtype glutamate receptors generated by polyamine-mediated ion channel block. Neuron 15, 453-462. doi: 10.1016/0896-6273(95)90049-7

Buckingham, B. P., Inman, D. M., Lambert, W., Oglesby, E., Calkins, D. J., Steele, M. R., et al. (2008). Progressive ganglion cell degeneration precedes neuronal loss in a mouse model of glaucoma. J. Neurosci. 28, 2735-2744. doi: 10.1523/JNEUROSCI.4443-07.2008

Calkins, D. J. (2012). Critical pathogenic events underlying progression of neurodegeneration in glaucoma. Prog. Retin. Eye Res. 31, 702-719. doi: 10.1016/j.preteyeres.2012.07.001

Chávez, A. E., Singer, J. H., and Diamond, J. S. (2006). Fast neurotransmitter release triggered by Ca influx through AMPA-type glutamate receptors. Nature 443, 705-708. doi: 10.1038/nature05123

Chen, H., Zhao, Y., Liu, M., Feng, L., Puyang, Z., Yi, J., et al. (2015). Progressive degeneration of retinal and superior collicular functions in mice with sustained ocular hypertension. Invest. Ophthalmol. Vis. Sci. 56, 1971-1984. doi: 10.1167/iovs.14-15691

Chevaleyre, V., and Castillo, P. E. (2004). Endocannabinoid-mediated metaplasticity in the hippocampus. Neuron 43, 871-881. doi: 10.1016/j. neuron.2004.08.036

Clem, R. L., and Barth, A. (2006). Pathway-specific trafficking of native AMPARs by in vivo experience. Neuron 49, 663-670. doi: 10.1016/j.neuron.2006.01.019

Clem, R. L., and Huganir, R. L. (2010). Calcium-permeable AMPA receptor dynamics mediate fear memory erasure. Science 330, 1108-1112. doi: $10.1126 /$ science. 1195298

Crish, S. D., Sappington, R. M., Inman, D. M., Horner, P. J., and Calkins, D. J. (2010). Distal axonopathy with structural persistence in glaucomatous neurodegeneration. Proc. Natl. Acad. Sci. U S A 107, 5196-5201. doi: 10.1073/pnas.0913141107

Cueva Vargas, J. L., Osswald, I. K., Unsain, N., Aurousseau, M. R., Barker, P. A., Bowie, D., et al. (2015). Soluble tumor necrosis factor $\alpha$ promotes retinal ganglion cell death in glaucoma via calcium-permeable AMPA receptor activation. J. Neurosci. 35, 12088-12102. doi: 10.1523/JNEUROSCI.1273-15. 2015

Cull-Candy, S., Kelly, L., and Farrant, M. (2006). Regulation of $\mathrm{Ca}^{2+}$-permeable AMPA receptors: synaptic plasticity and beyond. Curr. Opin. Neurobiol. 16, 288-297. doi: 10.1016/j.conb.2006.05.012

Della Santina, L., Inman, D. M., Lupien, C. B., Horner, P. J., and Wong, R. O. (2013). Differential progression of structural and functional alterations in distinct retinal ganglion cell types in a mouse model of glaucoma. J. Neurosci. 33, 17444-17457. doi: 10.1523/JNEUROSCI.5461-12.2013

Della Santina, L., and Ou, Y. (2017). Who's lost first? Susceptibility of retinal ganglion cell types in experimental glaucoma. Exp. Eye Res. 158, 43-50. doi: 10.1016/j.exer.2016.06.006

Dias, R. B., Rombo, D. M., Ribeiro, J. A., and Sebastião, A. M. (2013). Ischemiainduced synaptic plasticity drives sustained expression of calcium-permeable AMPA receptors in the hippocampus. Neuropharmacology 65, 114-122. doi: 10.1016/j.neuropharm.2012.09.016

Dittman, J. S., and Regehr, W. G. (1998). Calcium dependence and recovery kinetics of presynaptic depression at the climbing fiber to purkinje cell synapse. J. Neurosci. 18, 6147-6162. doi: 10.1523/JNEUROSCI.18-16-061 47.1998

Donevan, S. D., and Rogawski, M. A. (1995). Intracellular polyamines mediate inward rectification of $\mathrm{Ca}(2+)$-permeable alpha-amino-3-hydroxy-5-methyl-4isoxazolepropionic acid receptors. Proc. Natl. Acad. Sci. U S A. 92, 9298-9302. doi: 10.1073 /pnas.92.20.9298
Dong, L. D., Gao, F., Wang, X. H., Miao, Y., Wang, S. Y., Wu, Y., et al. (2015). GluA2 trafficking is involved in apoptosis of retinal ganglion cells induced by activation of EphB/EphrinB reverse signaling in a rat chronic ocular hypertension model. J. Neurosci. 35, 5409-5421. doi: 10.1523/JNEUROSCI. 4376-14.2015

Duan, X., Krishnaswamy, A., De la Huerta, I., and Sanes, J. R. (2014). Type II cadherins guide assembly of a direction-selective retinal circuit. Cell 158, 793-807. doi: 10.1016/j.cell.2014.06.047

Duan, X., Qiao, M., Bei, F., Kim, I. J., He, Z., and Sanes, J. R. (2015). Subtypespecific regeneration of retinal ganglion cells following axotomy: effects of osteopontin and mTOR signaling. Neuron 85, 1244-1256. doi: 10.1016/j. neuron.2015.02.017

El-Danaf, R. N., and Huberman, A. D. (2015). Characteristic patterns of dendritic remodeling in early-stage glaucoma: evidence from genetically identified retinal ganglion cell types. J. Neurosci. 35, 2329-2343. doi: 10.1523/JNEUROSCI.141914.2015

Field, G. D., and Rieke, F. (2002). Nonlinear signal transfer from mouse rods to bipolar cells and implications for visual sensitivity. Neuron 34, 773-785 doi: 10.1016/s0896-6273(02)00700-6

Frankfort, B. J., Khan, A. K., Tse, D. Y., Chung, I., Pang, J. J., Yang, Z., et al. (2013). Elevated intraocular pressure causes inner retinal dysfunction before cell loss in a mouse model of experimental glaucoma. Invest. Ophthalmol. Vis. Sci. 54, 762-770. doi: 10.1167/iovs.12-10581

Freed, M. A., Smith, R. G., and Sterling, P. (1992). Computational model of the on$\alpha$ ganglion cell receptive field based on bipolar cell circuitry. Proc. Natl. Acad. Sci. U S A 89, 236-240. doi: 10.1073/pnas.89.1.236

Hideyama, T., Yamashita, T., Aizawa, H., Tsuji, S., Kakita, A., Takahashi, H., et al. (2012). Profound downregulation of the RNA editing enzyme ADAR2 in ALS spinal motor neurons. Neurobiol. Dis. 45, 1121-1128. doi: 10.1016/j.nbd.2011. 12.033

Hideyama, T., Yamashita, T., Suzuki, T., Tsuji, S., Higuchi, M., Seeburg, P. H., et al. (2010). Induced loss of ADAR2 engenders slow death of motor neurons from Q/R site-unedited GluR2. J. Neurosci. 30, 11917-11925. doi: 10.1523/JNEUROSCI.2021-10.2010

Higuchi, M., Maas, S., Single, F. N., Hartner, J., Rozov, A., Burnashev, N., et al. (2000). Point mutation in an AMPA receptor gene rescues lethality in mice deficient in the RNA-editing enzyme ADAR2. Nature 406, 78-81. doi: $10.1038 / 35017558$

Holcombe, D. J., Lengefeld, N., Gole, G. A., and Barnett, N. L. (2008). Selective inner retinal dysfunction precedes ganglion cell loss in a mouse glaucoma model. Br. J. Ophthalmol. 92, 683-688. doi: 10.1136/bjo.2007.133223

Hong, I., Kim, J., Kim, J., Lee, S., Ko, H.-G., Nader, K., et al. (2013). AMPA receptor exchange underlies transient memory destabilization on retrieval. Proc. Natl. Acad. Sci. U S A 110, 8218-8223. doi: 10.1073/pnas.1305235110

Horsch, M., Calzada-Wack, J., Adler, T., Aguilar-Pimentel, J. A., Becker, L., Calzada-Wack, J., et al. (2011). Requirement of the RNA-editing enzyme ADAR2 for normal physiology in mice. J. Biol. Chem. 286, 18614-18622. doi: 10.1074/jbc.M110.200881

Hwang, J. Y., Aromolaran, K. A., and Zukin, R. S. (2013). Epigenetic mechanisms in stroke and epilepsy. Neuropsychopharmacology 38, 167-182. doi: $10.1038 /$ npp. 2012.134

Isaac, J. T., Ashby, M. C., and McBain, C. J. (2007). The role of the GluR2 subunit in AMPA receptor function and synaptic plasticity. Neuron 54, 859-871. doi: 10.1016/j.neuron.2007.06.001

Jones, R. S., Carroll, R. C., and Nawy, S. (2012). Light-induced plasticity of synaptic AMPA receptor composition in retinal ganglion cells. Neuron 75, 467-478. doi: 10.1016/j.neuron.2012.05.030

Ju, W., Morishita, W., Tsui, J., Gaietta, G., Deerinck, T. J., Adams, S. R., et al. (2004). Activity-dependent regulation of dendritic synthesis and trafficking of AMPA receptors. Nat. Neurosci. 7, 244-253. doi: 10.1038/nn1189

Kamboj, S. K., Swanson, G. T., and Cull-Candy, S. G. (1995). Intracellular spermine confers rectification on rat calcium-permeable AMPA and kainate receptors. J. Physiol. 486, 297-303. doi: 10.1113/jphysiol.1995.sp020812

Kerschensteiner, D., Morgan, J. L., Parker, E. D., Lewis, R. M., and Wong, R. O. (2009). Neurotransmission selectively regulates synapse formation in parallel circuits in vivo. Nature 460, 1016-1020. doi: 10.1038/nature08236

Kobylecki, C., Cenci, M. A., Crossman, A. R., and Ravenscroft, P. (2010). Calciumpermeable AMPA receptors are involved in the induction and expression of 1 - 
DOPA-induced dyskinesia in Parkinson's disease. J. Neurochem. 114, 499-511. doi: 10.1111/j.1471-4159.2010.06776.x

Koh, D. S., Burnashev, N., and Jonas, P. (1995). Block of native $\mathrm{Ca}^{2+}$. permeable AMPA receptors in rat brain by intracellular polyamines generates double rectification. J. Physiol. 486, 305-312. doi: 10.1113/jphysiol.1995. sp020813

Kreitzer, A. C., and Regehr, W. G. (2001a). Retrograde inhibition of presynaptic calcium influx by endogenous cannabinoids at excitatory synapses onto Purkinje cells. Neuron 29, 717-727. doi: 10.1016/s0896-6273(01)00246-x

Kreitzer, A. C., and Regehr, W. G. (2001b). Cerebellar depolarization-induced suppression of inhibition is mediated by endogenous cannabinoids. J. Neurosci. 21:RC174. doi: 10.1523/JNEUROSCI.21-20-j0005.2001

Krieger, B., Qiao, M., Rousso, D. L., Sanes, J. R., and Meister, M. (2017). Four $\alpha$ ganglion cell types in mouse retina: function, structure, and molecular signatures. PLoS One 12:e0180091. doi: 10.1371/journal.pone.0180091

Kwak, S., Hideyama, T., Yamashita, T., and Aizawa, H. (2010). AMPA receptormediated neuronal death in sporadic ALS. Neuropathology 30, 182-188. doi: 10.1111/j.1440-1789.2009.01090.x

Kwak, S., and Kawahara, Y. (2005). Deficient RNA editing of GluR2 and neuronal death in amyotropic lateral sclerosis. J. Mol. Med. 83, 110-120. doi: $10.1007 / \mathrm{s} 00109-004-0599-\mathrm{z}$

Kwak, S., and Weiss, J. H. (2006). Calcium-permeable AMPA channels in neurodegenerative disease and ischemia. Curr. Opin. Neurobiol. 16, 281-287. doi: $10.1016 /$ j.conb.2006.05.004

Lei, S., and McBain, C. J. (2004). Two Loci of expression for long-term depression at hippocampal mossy fiber-interneuron synapses. J. Neurosci. 24, 2112-2121. doi: 10.1523/JNEUROSCI.4645-03.2004

Lippman-Bell, J. J., Zhou, C., Sun, H., Feske, J. S., and Jensen, F. E. (2016). Earlylife seizures alter synaptic calcium-permeable AMPA receptor function and plasticity. Mol. Cell. Neurosci. 76, 11-20. doi: 10.1016/j.mcn.2016.08.002

Liu, S., Lau, L., Wei, J., Zhu, D., Zou, S., Sun, H.-S., et al. (2004). Expression of $\mathrm{Ca}^{2+}$-permeable AMPA receptor channels primes cell death in transient forebrain ischemia. Neuron 43, 43-55. doi: 10.1016/j.neuron.2004.06.017

Liu, S. Q., and Cull-Candy, S. G. (2000). Synaptic activity at calcium-permeable AMPA receptors induces a switch in receptor subtype. Nature 405, 454-458. doi: $10.1038 / 35013064$

Liu, S. J., and Savtchouk, I. (2012). $\mathrm{Ca}^{2+}$ permeable AMPA receptors switch allegiances: mechanisms and consequences. J. Physiol. 590, 13-20. doi: 10.1113/jphysiol.2011.213926

Liu, Y., Formisano, L., Savtchouk, I., Takayasu, Y., Szabo, G., Zukin, R. S., et al. (2010). A single fear-inducing stimulus induces a transcriptiondependent switch in synaptic AMPAR phenotype. Nat. Neurosci. 13, 223-231. doi: $10.1038 / \mathrm{nn} .2474$

Lomeli, H., Mosbacher, J., Melcher, T., Höger, T., Geiger, J. R., Kuner, T., et al. (1994). Control of kinetic properties of AMPA receptor channels by nuclear RNA editing. Science 266, 1709-1713. doi: 10.1126/science.7992055

Lorenzini, I., Moore, S., and Sattler, R. (2018). "RNA editing deficiency in neurodegeneration," in RNA Metabolism in Neurodegenerative Diseases, eds R. Sattler and C. J. Donnelly (Cham: Springer International Publishing), 63-83.

Margolis, D. J., and Detwiler, P. B. (2007). Different mechanisms generate maintained activity in ON and OFF retinal ganglion cells. J. Neurosci. 27, 5994-6005. doi: 10.1523/JNEUROSCI.0130-07.2007

Middleton, T. P., and Protti, D. A. (2011). Cannabinoids modulate spontaneous synaptic activity in retinal ganglion cells. Vis. Neurosci. 28, 393-402. doi: $10.1017 / \mathrm{s} 0952523811000198$

Morgan, J. L., Soto, F., Wong, R. O., and Kerschensteiner, D. (2011). Development of cell type-specific connectivity patterns of converging excitatory axons in the retina. Neuron 71, 1014-1021. doi: 10.1016/j.neuron.2011.08.025

Murphy, G. J., and Rieke, F. (2011). Electrical synaptic input to ganglion cells underlies differences in the output and absolute sensitivity of parallel retinal circuits. J. Neurosci. 31, 12218-12228. doi: 10.1523/JNEUROSCI.3241-11.2011

Najac, M., and Raman, I. M. (2017). Synaptic excitation by climbing fibre collaterals in the cerebellar nuclei of juvenile and adult mice. J. Physiol. 595, 6703-6718. doi: 10.1113/jp274598

Noh, K.-M., Yokota, H., Mashiko, T., Castillo, P. E., Zukin, R. S., and Bennett, M. V. L. (2005). Blockade of calcium-permeable AMPA receptors protects hippocampal neurons against global ischemia-induced death. Proc. Natl. Acad. Sci. U S A 102, 12230-12235. doi: 10.1073/pnas.0505408102
Ohno-Shosaku, T., Tsubokawa, H., Mizushima, I., Yoneda, N., Zimmer, A., and Kano, M. (2002). Presynaptic cannabinoid sensitivity is a major determinant of depolarization-induced retrograde suppression at hippocampal synapses. J. Neurosci. 22, 3864-3872. doi: 10.1523/JNEUROSCI.22-10-03864.2002

Ou, Y., Jo, R. E., Ullian, E. M., Wong, R. O., and Della Santina, L. (2016). Selective vulnerability of specific retinal ganglion cell types and synapses after transient ocular hypertension. J. Neurosci. 36, 9240-9252. doi: 10.1523/JNEUROSCI. 0940-16.2016

Pang, J. J., Frankfort, B. J., Gross, R. L., and Wu, S. M. (2015). Elevated intraocular pressure decreases response sensitivity of inner retinal neurons in experimental glaucoma mice. Proc. Natl. Acad. Sci. U S A 112, 2593-2598. doi: 10.1073/pnas. 1419921112

Piomelli, D. (2003). The molecular logic of endocannabinoid signalling. Nat. Rev. Neurosci. 4, 873-884. doi: 10.1038/nrn1247

Pitler, T. A., and Alger, B. E. (1992). Postsynaptic spike firing reduces synaptic GABAA responses in hippocampal pyramidal cells. J. Neurosci. 12, 4122-4132. doi: 10.1523/JNEUROSCI.12-10-04122.1992

Pitler, T. A., and Alger, B. E. (1994). Depolarization-induced suppression of GABAergic inhibition in rat hippocampal pyramidal cells: G protein involvement in a presynaptic mechanism. Neuron 13, 1447-1455. doi: 10.1016/0896-6273(94)90430-8

Rakhade, S. N., Zhou, C., Aujla, P. K., Fishman, R., Sucher, N. J., and Jensen, F. E. (2008). Early alterations of AMPA receptors mediate synaptic potentiation induced by neonatal seizures. J. Neurosci. 28, 7979-7990. doi: 10.1523/JNEUROSCI.1734-08.2008

Rao-Ruiz, P., Rotaru, D. C., van der Loo, R. J., Mansvelder, H. D., Stiedl, O., Smit, A. B., et al. (2011). Retrieval-specific endocytosis of GluA2-AMPARs underlies adaptive reconsolidation of contextual fear. Nat. Neurosci. 14, 1302-1308. doi: 10.1038/nn.2907

Risner, M. L., Pasini, S., Cooper, M. L., Lambert, W. S., and Calkins, D. J. (2018). Axogenic mechanism enhances retinal ganglion cell excitability during early progression in glaucoma. Proc. Natl. Acad. Sci. U S A 115, E2393-e2402. doi: 10.1073/pnas. 1714888115

Sappington, R. M., Carlson, B. J., Crish, S. D., and Calkins, D. J. (2010). The microbead occlusion model: a paradigm for induced ocular hypertension in rats and mice. Invest. Ophthalmol. Vis. Sci. 51, 207-216. doi: 10.1167/iovs. 09-3947

Savtchouk, I., and Liu, S. J. (2011). Remodeling of synaptic AMPA receptor subtype alters the probability and pattern of action potential firing. J. Neurosci. 31, 501-511. doi: 10.1523/JNEUROSCI.2608-10.2011

Schmidt, T. M., and Kofuji, P. (2011). An isolated retinal preparation to record light response from genetically labeled retinal ganglion cells. J. Vis. Exp. 47:e2367. doi: 10.3791/2367

Schwartz, G. W., Okawa, H., Dunn, F. A., Morgan, J. L., Kerschensteiner, D., Wong, R. O., et al. (2012). The spatial structure of a nonlinear receptive field. Nat. Neurosci. 15, 1572-1580. doi: 10.1038/nn.3225

Shukla, A., Beroun, A., Panopoulou, M., Neumann, P. A., Grant, S. G., Olive, M. F., et al. (2017). Calcium-permeable AMPA receptors and silent synapses in cocaine-conditioned place preference. EMBO J. 36, 458-474. doi: $10.15252 / \mathrm{embj} .201695465$

Singer, J. H., and Diamond, J. S. (2006). Vesicle depletion and synaptic depression at a mammalian ribbon synapse. J. Neurophysiol. 95, 3191-3198. doi: 10.1152 /jn.01309.2005

Sladek, A. L., and Nawy, S. (2019). Ocular hypertension drives remodeling of AMPA receptors in select populations of retinal ganglion cells. bioRxiv:743559 [Preprint]. doi: 10.1101/743559

Straiker, A., Stella, N., Piomelli, D., Mackie, K., Karten, H. J., and Maguire, G. (1999). Cannabinoid CB1 receptors and ligands in vertebrate retina: localization and function of an endogenous signaling system. Proc. Natl. Acad. Sci. U S A 96, 14565-14570. doi: 10.1073/pnas.96.25.14565

Sutton, M. A., Ito, H. T., Cressy, P., Kempf, C., Woo, J. C., and Schuman, E. M. (2006). Miniature neurotransmission stabilizes synaptic function via tonic suppression of local dendritic protein synthesis. Cell 125, 785-799. doi: 10.1016/j.cell.2006.03.040

Tao, X., Sabharwal, J., Seilheimer, R. L., Wu, S. M., and Frankfort, B. J. (2019). Mild intraocular pressure elevation in mice reveals distinct retinal ganglion cell functional thresholds and pressure-dependent properties. J. Neurosci. 39, 1881-1891. doi: 10.1523/JNEUROSCI.2085-18.2019 
Tien, N. W., Soto, F., and Kerschensteiner, D. (2017). Homeostatic plasticity shapes cell-type-specific wiring in the retina. Neuron 94, 656.e4-665.e4. doi: 10.1016/j.neuron.2017.04.016

van Wyk, M., Wässle, H., and Taylor, W. R. (2009). Receptive field properties of ON- and OFF-ganglion cells in the mouse retina. Vis. Neurosci. 26, 297-308. doi: 10.1017/s0952523809990137

Wan, Q. F., and Heidelberger, R. (2011). Synaptic release at mammalian bipolar cell terminals. Vis. Neurosci. 28, 109-119. doi: 10.1017/s0952523810 000453

Wang, A. L., Carroll, R. C., and Nawy, S. (2014). Down-regulation of the RNA editing enzyme ADAR2 contributes to RGC death in a mouse model of glaucoma. PLoS One 9:e91288. doi: 10.1371/journal.pone.0091288

Ward, N. J., Ho, K. W., Lambert, W. S., Weitlauf, C., and Calkins, D. J. (2014). Absence of transient receptor potential vanilloid-1 accelerates stressinduced axonopathy in the optic projection. J. Neurosci. 34, 3161-3170. doi: 10.1523/JNEUROSCI.4089-13.2014

Wen, X., Cahill, A. L., Barta, C., Thoreson, W. B., and Nawy, S. (2018). Elevated pressure increases $\mathrm{Ca}^{2+}$ influx through AMPA receptors in select populations of retinal ganglion cells. Front. Cell. Neurosci. 12:162. doi: 10.3389/fncel.2018. 00162

Whitehead, G., Regan, P., Whitcomb, D. J., and Cho, K. (2017). Ca ${ }^{2+}$-permeable AMPA receptor: a new perspective on amyloid- $\beta$ mediated pathophysiology of Alzheimer's disease. Neuropharmacology 112, 221-227. doi: 10.1016/j. neuropharm.2016.08.022

Wilson, R. I., and Nicoll, R. A. (2001). Endogenous cannabinoids mediate retrograde signalling at hippocampal synapses. Nature 410, 588-592. doi: $10.1038 / 35069076$

Wolf, M. E. (2016). Synaptic mechanisms underlying persistent cocaine craving. Nat. Rev. Neurosci. 17, 351-365. doi: 10.1038/nrn.2016.39
Xia, Y., Nawy, S., and Carroll, R. C. (2007). Activity-dependent synaptic plasticity in retinal ganglion cells. J. Neurosci. 27, 12221-12229. doi: 10.1523/JNEUROSCI.2086-07.2007

Yamashita, T., Chai, H. L., Teramoto, S., Tsuji, S., Shimazaki, K., Muramatsu, S., et al. (2013). Rescue of amyotrophic lateral sclerosis phenotype in a mouse model by intravenous AAV9-ADAR2 delivery to motor neurons. EMBO Mol. Med. 5, 1710-1719. doi: 10.1002/emmm.201302935

Yamashita, T., and Kwak, S. (2019). Cell death cascade and molecular therapy in ADAR2-deficient motor neurons of ALS. Neurosci. Res. 144, 4-13. doi: 10.1016/j.neures.2018.06.004

Yazulla, S., Studholme, K. M., McIntosh, H. H., and Deutsch, D. G. (1999). Immunocytochemical localization of cannabinoid CB1 receptor and fatty acid amide hydrolase in rat retina. J. Comp. Neurol. 415, 80-90. doi: 10.1002/(sici)1096-9861(19991206)415:1<80::aid-cne6>3.0.co;2-h

Yu, W. Q., El-Danaf, R. N., Okawa, H., Pacholec, J. M., Matti, U., Schwarz, K., et al. (2018). Synaptic convergence patterns onto retinal ganglion cells are preserved despite topographic variation in pre- and postsynaptic territories. Cell Rep. 25, 2017.e3-2026.e3. doi: 10.1016/j.celrep.2018.10.089

Conflict of Interest: The authors declare that the research was conducted in the absence of any commercial or financial relationships that could be construed as a potential conflict of interest.

Copyright (C) 2020 Sladek and Nawy. This is an open-access article distributed under the terms of the Creative Commons Attribution License (CC BY). The use, distribution or reproduction in other forums is permitted, provided the original author(s) and the copyright owner(s) are credited and that the original publication in this journal is cited, in accordance with accepted academic practice. No use, distribution or reproduction is permitted which does not comply with these terms. 